Spike Gildea* and Fernando Zúñiga

\title{
Referential hierarchies: A new look at some historical and typological patterns
}

DOI 10.1515/ling-2016-0007

Abstract: This paper proposes a diachronic typology for the various patterns that have been referred to as Hierarchical Alignment or Inverse Alignment. Previous typological studies have tried to explain such patterns as grammatical reflections of a universal Referential Hierarchy, in which first person outranks second person outranks third person and humans outrank other animates outrank inanimates. However, our study shows that most of the formal properties of hierarchy-sensitive constructions are essentially predictable from their historical sources. We have identified three sources for hierarchical person marking, three for direction marking, two for obviative case marking, and one for hierarchical constituent ordering. These sources suggest that there is more than one explanation for hierarchical alignment: one is consistent with Givón's claim that hierarchical patterns are a grammaticalization of generic topicality; another is consistent with DeLancey's claim that hierarchies reflect the deictic distinction between present (1/2) and distant (3) participants; another is simply a new manifestation of a common asymmetrical pattern, the use of zero marking for third persons. More importantly, the evolution of hierarchical grammatical patterns does not reflect a consistent universal ranking of participants - at least in those cases where we can see (or infer) historical stages in the evolution of these properties, different historical stages appear to reflect different hierarchical rankings of participants, especially first and second person. This leads us to conclude that the diversity of hierarchical patterns is an artifact of grammatical change, and that in general, the presence of hierarchical patterns in synchronic grammars is not somehow conditioned by some more general universal hierarchy.

Keywords: hierarchical grammar, typology, diachronic typology

\footnotetext{
*Corresponding author: Spike Gildea, Department of Linguistics, University of Oregon, Eugene, OR 97403-1290, USA, E-mail: spike@uoregon.edu

Fernando Zúñiga, Department of Linguistics, University of Bern, Laenggassstrasse 49, 3000 Bern 9, Switzerland, E-mail: fernando.zuniga@isw.unibe.ch
} 


\section{Introduction}

Readers of this issue will already be aware that a number of grammatical features in a number of languages are sensitive to semantic and pragmatic features of participants that are referenced via (or in association with) that grammar. The semantic and pragmatic features in question are usually arranged into a hierarchy, which is spoken of as though one and the same hierarchy were revealed in the distribution of each grammatical feature in each language. This hierarchy was originally described as the "lexical hierarchy" in Silverstein (1976: 116; Figure 1), and has since been relabeled and tinkered with multiple times, yielding labels such as the Animacy Hierarchy (Comrie 1989 [1981]), the Ontological Salience Hierarchy (Klaiman 1991), the Referential Hierarchy (Bickel 2008), the Topicality Hierarchy (Givón 1994, 2001) and as simply the Nominal Hierarchy, or NP Hierarchy (Dixon 1994; Figure 2).

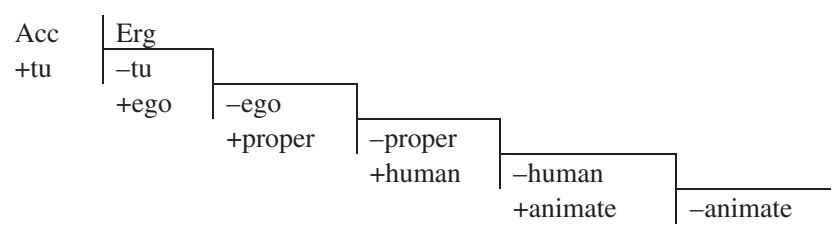

Figure 1: The "lexical hierarchy” (Silverstein 1976: 122).

$1>2>3$ PRONOUN $>3$ PROPER $>3$ HUMAN $>3$ ANIMATE $>3$ INANIMATE

Figure 2: The "Nominal Hierarchy" (Dixon 1994: 85).

It is possible to study each grammatical feature in isolation, for example focusing on only case-marking, verbal indexing, constituent order, number marking, etc. However, the most exciting revelations associated with the hierarchy are those found in languages with hierarchical indexation in main clause grammar, and especially in the subset of these languages that possess an entire DirectInverse distinction in main clause grammar, which combines verbal indexation, Obviative case marking, and direction morphemes in the verb. Patterns of alignment are generally more interesting exactly because it appears that multiple grammatical subsystems (such as case, verbal indexation, etc.) conspire to create more complex patterns, which are in turn claimed to reflect the deep reality of the hierarchy. 
When we began our research into how and where these phenomena emerge in the past, we expected to find several well-motivated pathways all leading to the same hierarchy, and thereby to show that we could better understand the synchronic unity of hierarchical grammar by studying the disparate changes that created it in different language families and geographical regions of the world. We expected to find that these developmental changes were motivated by a hierarchy that might exist independently of language, probably in some more basic level of human cognition. Instead, we kept finding an unexpected lack of consistency in the synchronic patterns that were attributed to the hierarchy; given this finding, it is perhaps not surprising that we did not encounter the expected conspiracy of developmental changes leading to synchronic systems consistent with the hierarchy. This has led us to re-assess the strength with which "the hierarchy" is reflected in synchronic grammar (inconsistently) and to question the reality of "the hierarchy" as a universal construct that serves to organize human cognition, and thus patterns in human language.

To us, this came as rather bad news. However, alongside our newfound pessimism, we have also found some good news: by examining the kinds of changes that lead to so-called hierarchical grammar, we now know (a bit) more about how these language-specific grammatical phenomena are related to features and/or categories like person, animacy, definiteness, and topicality. In particular, we have identified correlations between the grammar of several subtypes of modern hierarchical alignments and the grammar of the source constructions from which the modern constructions originate. This paper is a first effort to organize our initial findings into a sort of diachronic typology, in which we present these correlations. Before presenting these findings, however, we briefly define our terms and discuss the kinds of grammar that will be relevant in our individual reconstructions.

The first relevant set of terminology concerns the four quadrants of the interactional scenarios between first and second person - the speech act participants (SAPs) - and third persons (3). The easiest way to identify a hierarchical alignment system is to organize transitive clauses into Direct scenarios, where SAP actors (A) act on third person undergoers (P) (dark gray quadrant in Figure 3), versus Inverse scenarios, where third person actors act on SAP undergoers (light gray quadrant in Figure 3). The remaining two quadrants contain the Local scenarios, where both actor and undergoer are SAP, and the Nonlocal scenarios, where both actor and undergoer are third person (both unshaded in Figure 3). When these quadrants - especially the Direct and Inverse - organize main clause grammar into coherent formal oppositions, then the term hierarchical alignment is most likely to be appropriate. In Figure 3, we represent these grammatical oppositions in the abstract via outlines of the interactional 


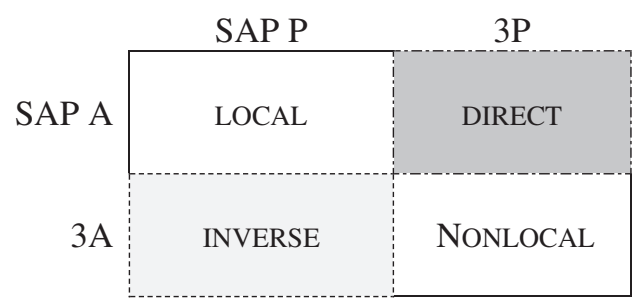

Figure 3: The four scenarios that commonly reflect hierarchical grammar.

scenarios where such grammar is encountered, with an uneven dashed line for direct grammar and an even dashed line for inverse grammar. Figure 3 thus represents an idealized system of hierarchical grammar, in which the grammar that marks the Direct situations is found only and entirely in the Direct quadrant (represented by the uneven dashed line circumscribing exactly the area shaded dark gray) whereas the grammar that marks the Inverse situations is found only and entirely in the Inverse quadrant (represented by the even dashed line circumscribing exactly the area shaded light gray).

The grammatical properties that combine into so-called hierarchical alignment systems begin with verbal indexation, in which the higher-ranking participant on the hierarchy controls verbal person marking. Alongside hierarchical indexation, we often find a direction marker, an opposition between Direct, which indicates that the action flows in the expected direction, from higher-ranking agent to lower-ranking patient, and Inverse, which indicates the opposite, that a higherranking patient is being acted upon by a lower-ranking agent. In the domain of dependent marking, when two third persons interact, the highest-ranked among them may be in the (usually unmarked) Proximate form, while the lower-ranked participant is in the Obviative form. In some cases, lower-ranked agents may bear ergative (or differential subject) marking and higher-ranked patients may bear accusative (or differential object) marking. These are seen as multiple reflections of the same hierarchy, and thus when a single clause type presents more than one of these phenomena, they are thought of as complex exponents of a single system. The diachronic question of interest is how these various exponents come to take their places in the individual main clause systems of individual languages.

In Section 2, we review the sources that have been identified so far for hierarchical alignment properties, beginning with those that were predicted, followed by those that were not. Givón (1994) suggests that his Semantic Inverse (most closely related to hierarchical alignment) always comes about by reanalysis of a Pragmatic Inverse, which comes in turn from reanalysis of a passive construction or a word order alternation (his "word-order inverse"); the reanalysis of 
passive voice constructions to hierarchical alignments is reconstructed multiple times in multiple language families and multiple geographical regions (Section 2.1), but the reanalysis of a word order alternation to hierarchical alignment remains unattested. DeLancey (2001) suggests that the Inverse is fundamentally deictic in nature, such that direction markers come about via reanalysis of markers that indicate physical direction of action, such as cislocative morphemes; we find multiple cases where this development is reconstructed, as well (Section 2.2), although none of these is accompanied by the genesis of hierarchical person-marking or differential case marking. In addition, we also find multiple cases of a much simpler (and less obviously motivated) phenomenon, which is simply the absence or loss of reconstructible third person subject and object indexes, leaving behind hierarchical indexation (Section 2.3). In addition, we have a single case in which a pair of reconstructed cleft constructions was reanalyzed as complementary Direct and Inverse clause types (Section 2.4). In some cases, more than one of these sources appears to contribute independently to the genesis of modern systems, and in many cases, contact appears to play a significant role. We discuss each of these points in the relevant subsections.

We are confident that this list does not exhaust the sources of modern hierarchical alignment systems, but the list is already sufficient to allow us to draw some theoretical implications, which we present in Section 3. We begin with the observation (reinforced in multiple papers in this volume) that the hierarchy is, in fact, not empirically well founded - that is, it appears that typologists have been eager to generalize about universal crosslinguistic patterns, but the facts of too many individual languages contradict any attempt to create a consistent crosslinguistic hierarchy (Section 3.1). Second, in cases where we have clear evidence of directional change, we see changes that explicitly create violations of the crosslinguistic hierarchy, showing that the hierarchy also fails to motivate specific historical changes in person indexing or dependent case-marking (Section 3.2). These two negative conclusions lead us to ask what is salvageable for typology. Our answer is that we can explain (in a post hoc way) the set of formal properties in the hierarchical alignment system of a given language as a function of the source(s) of the grammar in question. That is, rather than being shaped by a putative function that linguists have captured in a universal crosslinguistic hierarchy, the properties of these cases of hierarchical grammar follow more or less mechanically from their sources. This, then, allows us to push back the question of explanation to the domain of the selection of source construction and the mechanisms by which these sources evolve into the modern hierarchical alignment systems (Section 3.3).

Having introduced the major components of this paper, we turn now to the exposition of the various sources we have encountered in the literature. 


\section{Sources of so-called hierarchical alignment patterns}

This section begins with the two sources that have been predicted in the literature, then moves to two more sources that have not. In each case, we offer reconstructions based on prior work, both published and unpublished. Because our focus here is on the patterns themselves, we do not provide the details to justify the various reconstructions. For those details, we refer the reader to the published literature or else to past conference presentations that are in the process of being transformed into publications.

\subsection{Person sensitivization of passive constructions}

As predicted by Givón (1994), one of the sources of main clause hierarchical alignment is the overuse of passive constructions, so that they become common even in the case where A retains some topicality (agentive passive / inverse voice), and may even go on to become obligatory in the Inverse quadrant, thereby closely resembling canonical cases of hierarchical alignment. ${ }^{1}$ We rely on cases of "obligatory passives" in the literature, as summarized in typological work by Zúñiga (2006) and historical work by Mithun (2007, 2012). The mechanism predicted by Givón could be summarized as passage from a fully productive active-passive alternation, as schematized in Figure 4, to a system like that schematized in Figure 5, in which only the active construction is available in the Direct quadrant and only the passive construction in the Inverse quadrant. Note that Givón makes no prediction about what happens in the Local quadrant, and he assumes that a voice alternation remains in the Nonlocal quadrant, whether conditioned pragmatically or perhaps hardened into semantically conditioned selection (e. g., human > animate > inanimate), and as such, in Figure 5 we show no predicted changes in these two quadrants.

\footnotetext{
1 Unlike the (canonically intransitive) passive construction, both the DIRECT and the INVERSE CONSTRUCTIONS are understood here as transitive. Although we do not have clear evidence of syntactic transitivity for the erstwhile inverse construction in all of the languages discussed in this section, for the purposes of exposition, we will assume that a formally passive construction is likely to already be grammatically transitive when it is obligatorily used to express a clearly transitive argument structure. That said, whether an obligatory passive in the inverse personal/ actional quadrant corresponds to an inverse construction in a given language is an empirical issue.
} 


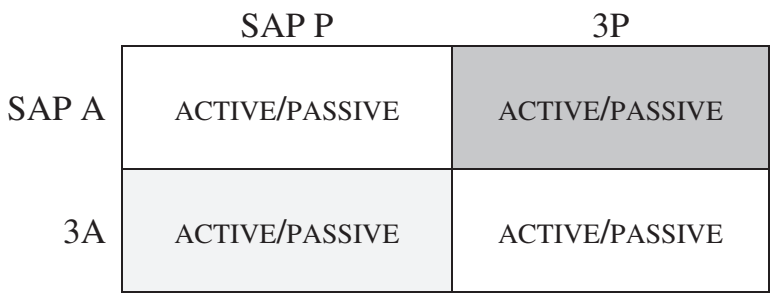

Figure 4: No hierarchy - passive and active in all quadrants.

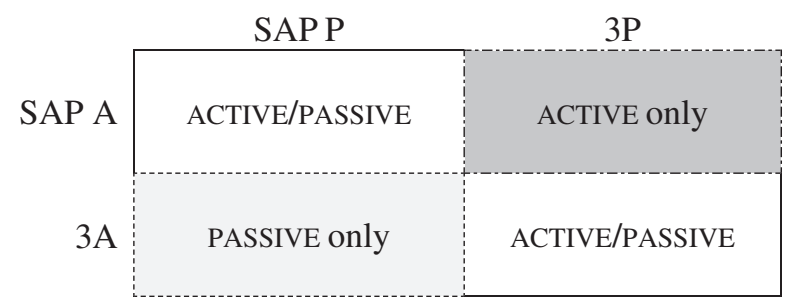

Figure 5: Active becomes Direct and passive becomes Inverse.

Changes of the sort predicted by Givón have, in fact, been claimed to be the source of patterns in which languages require the speaker to use an "obligatory active" or an "obligatory passive", depending upon who is acting on whom. ${ }^{2}$ As part of an argument for the areal spread of hierarchical main clause grammar, Mithun (2007) describes synchronic patterns of obligatory voice in three language families of the Pacific Northwest: Wakashan, Chimakuan, and Salish. As part of his survey of synchronic Inverse systems in the Kiowa-Tanoan language family, Zúñiga (2006) describes synchronic patterns of obligatory voice in Arizona Tewa and Southern Tiwa. In a paper inspired by the same sort of changes described in Mithun (2007), Mithun (2012) argues that the asymmetrical use of passive constructions in four unrelated languages of northern California also creates a hierarchical pattern of obligatory voice. Without repeating the many examples from these three works, we simply characterize the attested restrictions in voice alternation in terms of the schema given in Figure 5.

2 We leave open the question of whether these cases are better analyzed as the "obligatory passive" that they are called in many analyses (including in Mithun's work), or whether their obligatory status indicates that they are now (at least in these obligatory contexts) now better analyzed as transitive predications, something that is usually criterial in the definition of an inverse construction. 
We begin with Quileute (Chimakuan; Mithun 2007), a language that has only created obligatory voice in half of the Inverse domain, and thus which arguably has an extremely limited hierarchy: $2>3$. As seen in Figure 6, the passive is obligatory only when $3 \mathrm{~A}$ acts on $2 \mathrm{P}$ and the active is obligatory only when $2 \mathrm{~A}$ acts on $3 \mathrm{P}$. The Local quadrant does not participate in the alternation because neither active nor passive is allowed, but instead, the verb marks both participants. The active-passive alternation continues to be viable in the Nonlocal quadrant, as well as when $1 \mathrm{~A}$ acts on $3 \mathrm{P}$ and $3 \mathrm{~A}$ acts on $1 \mathrm{P}$.

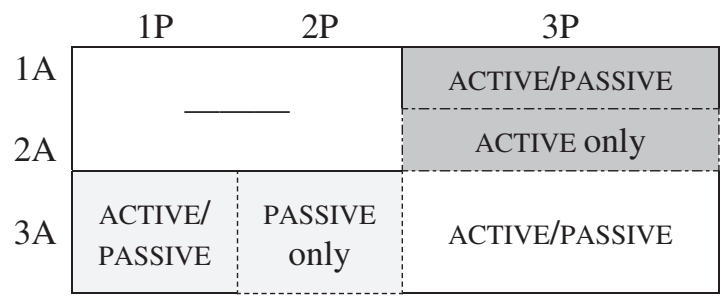

Figure 6: Limited hierarchical voice alternations in Quileute.

In neighboring languages Nitinaht and Makah (both Wakashan; Mithun 2007), the hierarchical grammar is more pervasive, with active voice obligatory throughout the Direct quadrant and passive voice obligatory throughout the Inverse quadrant, as schematized in Figure 7. As was the case in Quileute, in Nitinaht and Makah, the Local quadrant does not participate in either voice construction, instead marking both arguments directly on the verb; similarly, the Nonlocal quadrant continues to allow the voice alternation to occur.

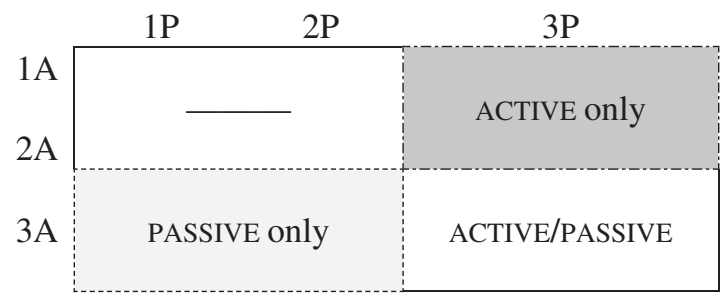

Figure 7: Canonical hierarchical voice alternations in Nitinaht and Makah.

To illustrate some of the typological flexibility of the Local domain, we have examples of all Local interactions becoming obligatory active voice in Southern Tiwa (Tanoan; Zúñiga 2006) and Nuuchahnulth (Wakashan; Mithun 2007), as modeled in Figure 8. Conversely, we have examples of all Local interactions 


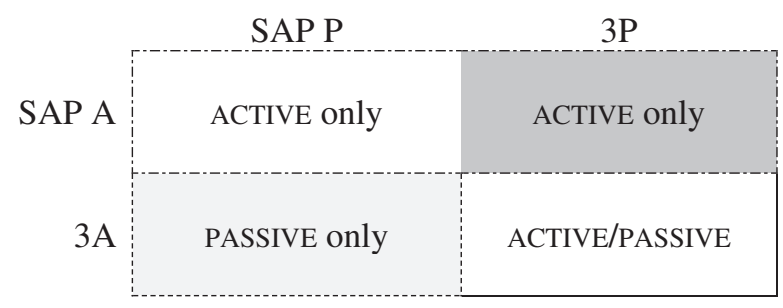

Figure 8: Extended hierarchical voice alternations in Southern Tiwa and Nuuchahnulth.

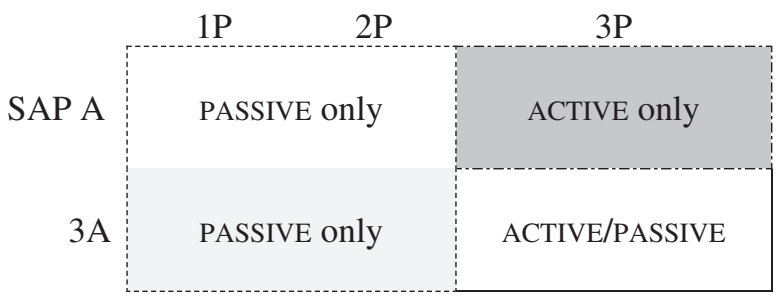

Figure 9: Extended hierarchical voice alternations in Arizona Tewa and Yana.

becoming obligatory passive in Yana (Northern California isolate; Mithun 2012), as modeled in Figure 9. ${ }^{3}$

These modern obligatory voice patterns appear to be perfect examples of Givón's predicted mechanism for the creation of inverse systems. It is not that speakers are creating new grammar, but by restricting the environments in which prior voice constructions may be used, the effect is precisely to create a hierarchical alignment system, in which the SAP participant will be marked as a subject in preference to third person, regardless of semantic role: it will be the A subject of a transitive clause and the $\mathrm{P}$ subject of a passive clause. This must have begun as a discourse preference, which then, in a gradual process, became obligatory. While it is the case that these patterns of usage appear to have spread by contact in both the Pacific Northwest Coast region and in northern California (cf. Mithun 2007, 2012), it is still the case that contact does not explain

3 Note that Arizona Tewa (Tanoan; Zúñiga 2006) also has a pattern in which all Local interactions are coded with the inverse construction, but we do not include it here for three reasons. First, the Arizona Tewa inverse construction is clearly not a synchronic passive (as argued in Klaiman 1991: 209). Second, even though related languages do instantiate the hierarchy via obligatory passives, we have yet to see a convincing argument that the Arizona Tewa Inverse comes from a passive. Third, the inverse construction is not required for $3 \rightarrow 1$ in Arizona Tewa, and so the overall system actually would require a figure of its own to map the distribution of constructions. 
the uniformity of the hierarchical outcome in the Direct and Inverse quadrants in both regions, plus in Arizona in Southern Tiwa. Note that this source of hierarchical alignment patterns does not show similarly uniform results in the Local quadrant, where $1=2,1>2$, and $2>1$ are all attested outcomes. Framing this in terms of a diachronic typology of hierarchical systems, we could say that the type of hierarchical alignment derived from an active-passive alternation will show multiple grammatical properties: (i) There will be an Inverse direction morpheme or construction, in that the prior passive morphology will be reanalyzed as Inverse. (ii) There will be a special "Obviative" marker on the Obviative A, which will come from the oblique marker on the A-phrase of the passive; the Proximate argument will align with the intransitive $S$, in that all three will be subjects of their etymological constructions ( $S$ of the intransitive clause, A of the active transitive clause, and $\mathrm{P}$ of the passive clause). ${ }^{4}$ The hierarchical grammar that distinguishes Direct from Inverse will also operate in the Nonlocal domain, and may or may not operate in the Local domain. Finally, the source of the observed hierarchical effects will originate from topicality, meaning we do not predict obligatory use of one or the other voice distinction in any subpart of the Nonlocal domain. ${ }^{5}$

\subsection{Reanalysis of deictic verbal morphology}

This mechanism was first expounded in DeLancey (2001), in support of his claim that the primary function of hierarchical alignment is to distinguish between first and second person, which are by definition at the deictic center of the speech act, in opposition to third person participants, which are not. The grammatical distinction that marks action in the direction of speech act participants is thus deictic in origin, either a cislocative (Section 2.2.1) or an incorporated verb of giving (Section 2.2.2). Since this sort of opposition is not as well known typologically as the active-passive opposition, in this section we illustrate the relevant constructions with language data.

4 Note that it is also possible to analyze this "obligatory passive" as an ergative main clause construction, given that P and S align. It is for this reason that Givón (1994) argues that the reanalysis of passive as a "pragmatic inverse" is a necessary step in the transition between the agent-suppressing function of passive and the resultant ergative construction in cases where passive > ergative (cf. also Dahl 2016 for a clear illustration of this in Vedic).

5 By saying we do not predict such effects, we merely assert that such extensions to the system are not necessary. Of course, Givón does predict that such extension could also arise in the Nonlocal domain, given that, to humans, e. g., other humans are inherently more topic worthy than other animate beings, which are inherently more topic worthy than inanimate beings, etc. 


\subsubsection{Cislocative > Inverse/Local marker}

This development path appears to be found in languages that are neither areally nor genealogically related. In Sizang and Tiddim (Tibeto-Burman), for instance, the function of the cislocative element hong "hither" (1a) has been extended to encompass action proceeding toward a 1st or 2nd person (either Inverse (1b)-(1c) as hong, or Local (1d)-(1e) as hong for $2 \rightarrow 1$ and kong (apparently the combination of 1 st person $k(a)$ - plus hong) for $1 \rightarrow 2$. We illustrate only with Sizang examples:

(1) Sizang (Kuki-Chin, Tibeto-Burman; Myanmar) ${ }^{6}$

a. Băng hóng há:i ní: zí:am?

why hither tardy 2sG Q

"Why have you (sG) come late?"

b. Hong sá:t thê:i lê:?

INV beat ever $Q$

"Do they ever beat you (sG)?"

c. Tî:a pal lé=ng, hong té:i tû:.

return early if $=1 \mathrm{sG}$ INV scold will

"If I come home early, they'll scold me."

d. Ka-sí:a băng hang hóng púak ngôl ní: zî:am?

1SG.PSR-tax why reason $2 \rightarrow 1$ send NEG 2SG Q

"Why didn't you (sG) send me my tax?"

e. Na-sí:a kóng púak aa.

2SG.PSR-tax $1 \rightarrow 2$ send NFIN

"I sent your tax to you (SG)."

(Stern 1984: 48-56)

A similar phenomenon is found in the western USA. In Molalla (unclassified) and Nez Perce (Sahaptian), the cislocative suffix $-m$ marks verbs with a 1st

6 Abbreviations: A Agentive core argument, AB Absential, ACT Active, AGT Agentive, ART Article, CAUS Causative, CIS Cislocative, CL Classifier, CO Co-participant, DIR Direct, DSC Discontinuative, EVID Evidential, F Feminine, FUT Future, INCL Inclusive, INSTR Instrumental, INV Inverse, LV Linking Vowel, M Masculine, MID Middle, N Neuter, NEG Negation, NFIN Nonfinite, NMLZ Nominalization, NPST Nonpast, OBL Oblique, OBV Obviative, P Patientive core argument, PASS Passive, PAT Patientive, PL Plural, PRO Pronoun, PROX Proximate, PSR Possessor, PST Past, Q Question, RE Referential Expression, REFL Reflexive, RP referential phrase, S Single core argument, SAP Speech Act Participant, SG Singular, SUBJ Subject, TP Transition Particle 
person P. ${ }^{7}$ In Molalla (2a), this happens with any A (Pharris 2006), whereas in Nez Perce (2b) the marker occurs only with a 2nd person A (Rude 1985):

(2) Molalla (Pharris 2006: 141)

a. N-pay-sla-m-i.

1sG.P-kill-FuT-cIs-3.S

"She will kill me."

b. Nez Perce (Noel Rude, p.c.)

$\begin{array}{ll}\emptyset \text {-'ewí-m-e } & \text { 'íine. } \\ \text { SAP.S/A-shoot-cIS-PST } & 1 \mathrm{sg} . P \\ \text { "You (sG) shot me.” } & \end{array}$

\subsubsection{Incorporated verb of giving > Inverse/Local marker}

Some Kondh languages belonging to the south-central branch of Dravidian (Kui, Kūvi, Manda, and Pengo) show a so-called transition particle (TP) that occurs in tense-marked non-reflexive verbs if the object is 1st or 2nd person (i.e., in Inverse and Local interactions). The several allomorphs $a, t a, d a$ (which appears as - $d$ in (3) below), $d a$, and ja of this marker can be traced back to a verb ${ }^{*} t \bar{a} /$ tara "give/bring to me or you"; an originally compound-verb construction consisting of this person-specific verb of giving and a main lexical verb was apparently univerbated through syntactic contraction, phonological reduction, and morphological reanalysis (Steever 1993: Ch. 2):

(3) Kui (South-Central Dravidian; India)
a. Hur-d-av-at-an.
see-TP-NEG-PST-3SG.M
"He did not see me/us."
b. Hur-d-av-at-ang.
see-TP-NEG-PST-1sG
"I did not see you."
(DeLancey 2001)

Putting the more robust examples, those of Sizang, Tiddim, and South-Central Dravidian into our quadrant schema (Figure 10), we see that both sources create a

7 Berman (1996) makes a strong case in favor of the inclusion of Molalla in Plateau Penutian. If Sahaptian is indeed part of this (still somewhat controversial) linguistic group, the cislocatives in Molalla and in Nez Perce are actually cognate. 


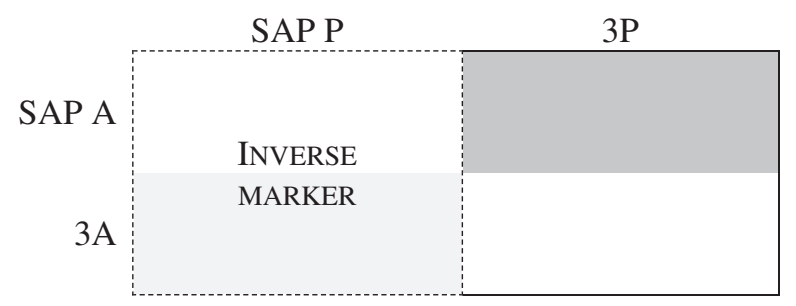

Figure 10: Deictic direction marking of actions with SAP P in Kuki-Chin and Dravidian.

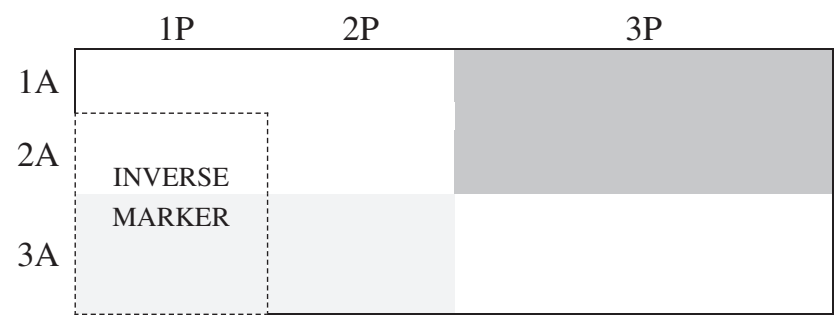

Figure 11: Deictic direction marking of first person $\mathrm{P}$ in Molalla.

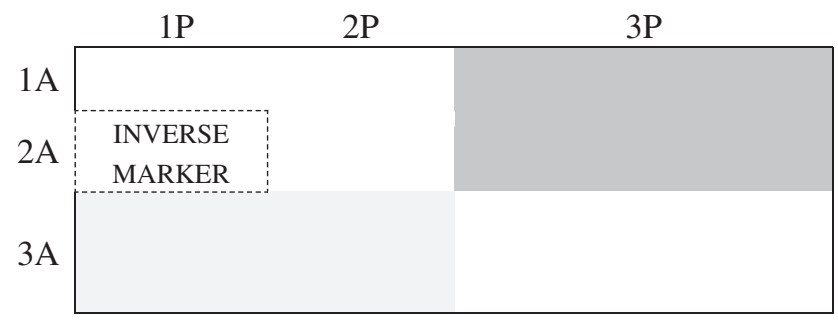

Figure 12: Deictic direction marking only of $2 \rightarrow 1$ in Nez Perce.

two-way distinction, marking clauses with a first or second person $\mathrm{P}$ and not marking clauses with a third person $\mathrm{P}$, without regard to the identity of A. Putting the less robust examples of Molalla (Figure 11) and Nez Perce (Figure 12) into the same schema, we see the pattern limited to first person P (Figure 11), or even more limited, to first person $\mathrm{P}$ uniquely when $\mathrm{A}$ is second person (Figure 12).

Compared to the passive source, the deictic source leads to quite limited effects in the grammar. As DeLancey (2001) notes, in none of these cases is there a change in the morphosyntax of grammatical relations, but merely the creation of a special marker of direction, limited to situations in which the action is aimed at a speech act participant. Such a source probably only gives rise to a 
direction marker; additional hierarchical patterns (e. g., hierarchical indexation, Obviative case marking) would need to come from other source material. We turn now to a source that yields a similarly limited outcome, only hierarchical indexation.

\subsection{Reanalysis of zero 3rd person forms}

Alongside these two functionally motivated sources we also find a source that yields hierarchical effects that are largely epiphenomenal, apparently mostly a consequence of the fact that zero-marking of third person participants is crosslinguistically far more frequent than for other persons (cf. Siewierska 2004: 5-6). This source has arguably given rise to hierarchical verb agreement patterns throughout the Cariban and Tupí-Guaraní families of South America (Section 2.3.1) and also may have played a role in the genesis of part of the hierarchical indexation patterns in the Mayan language Huastec (Section 2.3.2). A variant of this source also appears to have led to hierarchical verb agreement in Tacanan language Reyesano (Section 2.3.3).

\subsubsection{Cariban and Tupí-Guaraní}

The Cariban and Tupí-Guaraní families are well known for their hierarchical agreement, with one or the other or both having been cited in various typological treatments as examples of the type (Derbyshire 1987; Zavala 1994; Dixon 1994; Gildea 1998, 2012). In both families, the verb agrees with the SAP core argument as opposed to the third person, using distinct forms to indicate that the role is A or P (with the third person understood to be in the other role).

Beginning with the Cariban case, we present the reconstructed ProtoCariban person paradigm in Table 1 (adapted from Gildea 1998: 80). When $\mathrm{SAP} \rightarrow 3$ (the Direct quadrant), the verbal prefix indicates only the SAP A (as seen by comparison with the $S_{A}$ prefixes in the column to the right), whereas when $3 \rightarrow$ SAP (the Inverse quadrant), the verbal prefix indicates only the SAP P (as seen by the identical set of $S_{\mathrm{p}}$ prefixes in the row below). The Local quadrant contains a single prefix ${ }^{*} k(i)$-, which does not distinguish $2 \rightarrow 1$ from $1 \rightarrow 2$, and in all three situations that have only third person participants $\left(3 \mathrm{~S}_{\mathrm{A}}, 3 \mathrm{~S}_{\mathrm{P}}\right.$, and $\left.3 \rightarrow 3\right)$, the same prefix ${ }^{*} n(i)$ - occurs. We could readily characterize this in our quadrant schema as in Figure 13, where we see that the SAP A prefixes exactly fill the Direct quadrant, the SAP P prefixes fill the Inverse quadrant, and the Local and Nonlocal quadrants are each unique in having a single form each. 
Table 1: Reconstructed verbal person paradigm for Proto-Cariban.

\begin{tabular}{llllll}
\hline & $1 \mathbf{P}$ & $\mathbf{2 P}$ & $\mathbf{1}+\mathbf{2 P}$ & $\mathbf{3 P}$ & $\mathbf{S}_{\mathrm{A}}$ \\
\hline $1 \mathrm{~A}$ & & ${ }^{*} k(i)-$ & & ${ }^{*} t(i)-$ & ${ }^{*} w(i)-$ \\
$2 \mathrm{~A}$ & ${ }^{*} k(i)-$ & & & ${ }^{*} m(i)-$ & ${ }^{*} m(i)-$ \\
$1+2 \mathrm{~A}$ & & & & ${ }^{*} k+t(i)-$ & ${ }^{*} k+t(i)-$ \\
$3 \mathrm{~A}$ & ${ }^{*} u(j)-$ & ${ }^{*} a(j)-$ & ${ }^{*} k(i)-$ & ${ }^{*} n(i)-$ & ${ }^{*} n(i)-$ \\
$\mathrm{S}_{\mathrm{P}}$ & ${ }^{*} u(j)-$ & ${ }^{*} a(j)-$ & ${ }^{*} k(i)-$ & ${ }^{*} n(i)-$ & \\
\hline
\end{tabular}

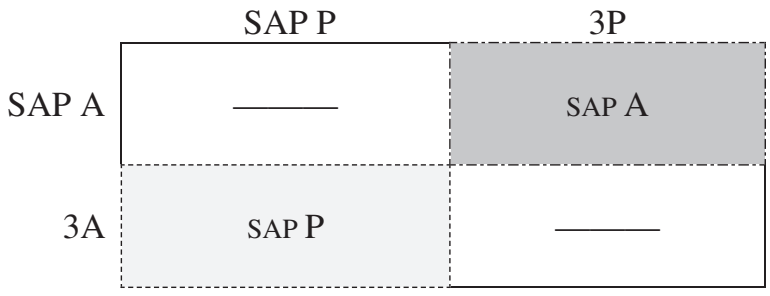

Figure 13: The Proto-Cariban prefixes as a hierarchical system.

Via comparative and internal reconstruction, Gildea (2012) posits that the source of this case of hierarchical agreement is fairly simple: there was no marker of $3 \mathrm{~A}$ (or if there was, by Proto-Cariban it had already eroded to a zero form), meaning all cases of $3 \rightarrow$ SAP already had only the morphological marker for the P. In the Direct quadrant, there was an older $3 \mathrm{P}$ prefix ${ }^{*} i$ - trapped between the SAP A markers and the stem. This ${ }^{*} i$ - disappeared in most modern Cariban languages (sometimes leaving behind changes to the stem-initial vowel, cf. Meira et al. 2010). With the loss of this third person $P$ form, the remaining prefix indicated only the SAP A. This story has many details that we do not present here (cf. Gildea 2009, 2012, 2013 for these), but for now, the crucial point is that the modern hierarchical agreement appears to be an unmotivated result of simple phonological erosion of this older 3P form.

As a postscript to this story, we add that in three modern languages, some Direct and/or Inverse prefixes have extended into the Local quadrant, creating an apparent ranking of first and second person. We show one such case in Table 2, that of Panare (adapted from Payne and Payne 2013: 200-204, supplemented with Gildea's field notes). Note that in Panare the split intransitive system is largely lost, as are the $1+2 \mathrm{~A}$ and $1+2 \mathrm{P}$ prefixes, making Table 2 much simpler than Table 1 . Looking first at the prefix $m(\dot{i})^{\wedge}{ }_{-}^{\prime} 2 \rightarrow 1$ ' we see the $2 \mathrm{~A}$ prefix $m(\dot{i})$ - plus a stress shift (graphically represented as ${ }^{{ }^{-}}$) ) associated with first person $\mathrm{P}$; while this is perhaps 
Table 2: The modern Panare verbal person paradigm.

\begin{tabular}{llll}
\hline & $1 \mathbf{P}$ & $\mathbf{2 P}$ & $3 \mathbf{P}$ \\
\hline $1 \mathrm{~A}$ & & $t(i)-$ & $t(i)-$ \\
& & $k(i)-$ & \\
$2 \mathrm{~A}$ & $m(i)^{\wedge}-$ & & $m(i)-$ \\
$3 \mathrm{~A}$ & $\wedge(j)-$ & $a(j)-$ & $n(i)-$ \\
\hline
\end{tabular}

best analyzed as double marking of $\mathrm{A}$ and $\mathrm{P}$, the segmental substance of the personal prefix selected is that of $2 \mathrm{~A}$ rather than $1 \mathrm{P}$. Turning to the possibilities attested for $1 \rightarrow 2$, we see two: a conservative reflex of Proto-Cariban ${ }^{\star} k(i)$ - and the $1 \mathrm{~A}$ prefix $t(\dot{i})$ - (which is immediately preceded by the second person $\mathrm{P}$ pronoun in all of Payne and Payne's examples). Given that the 2A prefix extends fully into the Local domain to code $2 \rightarrow 1$, whereas the $1 \mathrm{~A}$ prefix has only partially replaced the earlier SAP only prefix to code $1 \rightarrow 2$, for Figure 14 we put the $2 \mathrm{~A}$ above $1 \mathrm{~A}$ and the $2 \mathrm{P}$ to the left of $1 \mathrm{P}$, so as to make the schema model the hierarchy $2>1>3$.

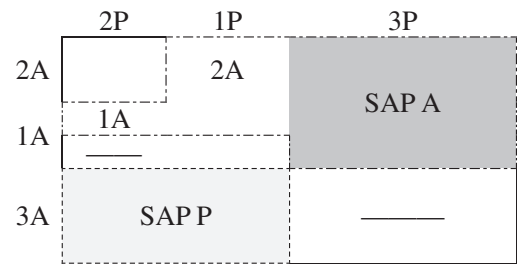

Figure 14: The Panare prefixes as a hierarchical system: $2>1>3$.

Looking at Figure 14, we see that the marking which originated in the Direct quadrant has extended leftward into the Local quadrant via the $2 \mathrm{~A}$ form for $2 \rightarrow 1$ and the possibility of the $1 \mathrm{~A}$ form for $1 \rightarrow 2$. At the same time, the conservative unique SAP form remains an option as well. We interpret this to mean that the Panare system is in the midst of change, one that might result in a consistent Direct pattern for $1 \rightarrow 2$, but given the lack of information about when speakers use one form in preference to the others, there is no way to predict whether the innovative $1 \rightarrow 2$ form might become the new standard, or indeed whether another change entirely might not arise. If the $1 \mathrm{~A}$ form were to become the new standard, then we would have another case of Local $=$ Direct, like the cases of Southern Tiwa and Nuuchahnulth in Figure 8 . If, instead, the $2 \mathrm{P}$ form were to begin being used when $1 \rightarrow 2$, then the Panare alignment system would become a consistent $2>1>3$ hierarchy.

For reasons of space, we do not give the Tupí-Guaraní forms here, but we consider the evolution to be quite similar to the Cariban case (cf. Jensen 1998 for 
reconstructed forms in Proto-Tupí-Guaraní, Gildea 2002, 2009 and Rose 2013 for reconstructions of the hierarchical personal prefixes). Like in the Cariban example, in Proto-Tupí-Guaraní there is simply no 3A form alongside the SAP P forms and there is a reconstructible 3P form that disappears in most modern languages. Unlike in the Cariban example, the Local forms are distinguished, with portmanteau prefixes for the various $1 \rightarrow 2$ cells, but simple 1 P prefixes for the various $2 \rightarrow 1$ cells, showing that hierarchical indexation in Tupí-Guaraní ranks first and second person vis-à-vis each other: $1>2>3$. In an exact parallel to the Cariban case, what distinguishes the Inverse quadrant is the absence of a reconstructible $3 \mathrm{~A}$ prefix, whereas what makes the Direct distinctive is the loss of a reconstructible $3 \mathrm{P}$ prefix.

Both these examples result in the same sort of typological profile: the personal prefix system in the verb codes only one participant, with one set of prefixes coding the SAP A in the Direct quadrant and a different set coding SAP $P$ in the Inverse quadrant; prefixes in the Local quadrant may be portmanteau or may select one of the SAP arguments to privilege. This source of hierarchy effects generates no direction marker, no Obviative case-marker, and no voice alternation in the Nonlocal quadrant.

\subsubsection{Deixis + Ø- “3” becomes hierarchical indexing in Huastec (Mayan)}

In the case of Huastec (Zavala 1994), ${ }^{8}$ we see a system that is clearly innovative. Table 3 shows the modern San Luis de Potosino (SLP) Huastec proclitics, ${ }^{9}$ as presented in Zavala (1994: 48, 58), whereas Table 4, following Zavala (1994: 68), shows how these proclitics are distributed in both transitive clauses (the top five rows) and intransitive clauses (the sixth row). Figure 15 models these distributions in terms of our four quadrants.

Note that the Direct and Nonlocal quadrants have only proclitics from Set A, whereas the Inverse quadrant has only proclitics from Set B. The Local quadrant has three patterns, which allow us to rank Speech Act Participants relative to one another. For $2 \rightarrow 1$, only the first person Set B proclitics appear, categorizing such interactions as a part of the Inverse indexation pattern; from this pattern, we can confidently state that 1 outranks 2 on the hierarchy. For $1 \rightarrow 2$, in all four cases the 1sG Set A proclitic occurs, confirming our ranking of $1>2$. However, while it is the

8 Since we originally wrote this section of the paper, Kondić (2012) has defended a reference grammar thesis on Huastec. We look forward to the additional insights that will follow from the more detailed description in that work.

9 In most Mayan languages, cognate person forms are encountered: Mayanist traditions labels them Set A (usually marking the ergative) and Set B (usually marking the absolutive). More on this shortly. 
Table 3: Sets of SLP Huastec proclitics.

\begin{tabular}{lll}
\hline & Set $\mathbf{A}$ & Set $\mathbf{B}$ \\
\hline $1 \mathrm{SG}$ & $u$ & in \\
$1 \mathrm{PL}$ & $i$ & $u$ \\
$2 \mathrm{SG}$ & $a$ & $i t$ \\
$2 \mathrm{PL}$ & $a$ & $i x / i t^{10}$ \\
3 & in & $\varnothing / u^{11}$ \\
\hline
\end{tabular}

Table 4: The distribution of SLP Huastec proclitics.

\begin{tabular}{llllll}
\hline & 15GP & 1PLP & 2PLP & 25GP & 3P \\
\hline 15GA & & & $t-(i x-) u$ & $t-u$ & $u$ \\
1PLA & & & $t-(i x-) u$ & $t-u$ & $i$ \\
2SGA & $t-i n$ & $t-u$ & & & $a$ \\
2PLA & $t-i n$ & $t-u$ & & & $a$ \\
$3 \mathrm{~A}$ & $t-i n$ & $t-u$ & $t-i-$ & $t-i$ & $i n$ \\
& & & & & \\
$\mathrm{~S}$ & in & $u$ & $i x / i t$ & $i t$ & $\varnothing / u$ \\
\hline
\end{tabular}

only person marker when $1 \rightarrow 2 \mathrm{sg}$ (making it a clear case of the Direct indexation pattern), for $1 \rightarrow 2 \mathrm{PL}$ it is optionally preceded by one of the 2PL Set B proclitics; this pattern leads us to exclude the $1 \rightarrow 2 \mathrm{PL}$ case from the set of Direct patterns, and thereby allows us to state that 2PL $>2 \mathrm{sG}$ on the hierarchy. Thus, the full hierarchy indicated by the proclitic indexation is $1>2 \mathrm{PL}>2 \mathrm{SG}>3$ (modeled in Figure 15).

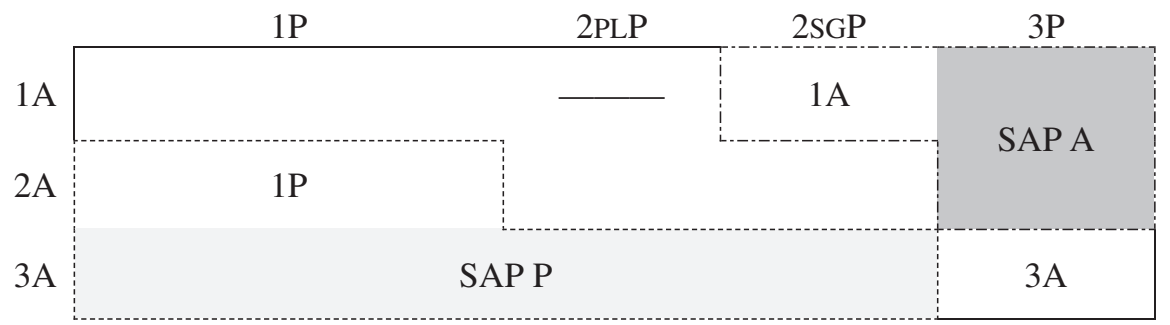

Figure 15: The modern indexation domains of SLP Huastec.

10 Zavala reports (p. 49) that these two forms are sociological variants: "The morpheme it is used by speakers of all ages; $i x$ is used only by old speakers as a reverential form."

11 Zavala reports (p.51) that $u$ and $\emptyset$ "B3" are allomorphs, with $u$ functioning only as the subject of monovalent verbal predicates in the incompletive form, and the form $\emptyset$ in all other environments (including in apparent free variation in the intransitive incompletive form). 
Also note that all person-markers in the Inverse and Local quadrants are preceded by the prefix $t$-, which Zavala (1994: 69) analyzes as an Inverse direction marker (modeled in Figure 16). This morpheme therefore defines a different hierarchy than that found in person indexation: that is, while the $1 \rightarrow$ 2sG form is indicated only by the first person Set A proclitic, which is a Direct pattern, the prefix $t$ - "INVERSE" also marks the $1 \mathrm{~A}$ proclitic, thus giving it the same formal treatment as the prefixes that belong to the inverse pattern. From this, we see that it is possible for different grammatical patterns in a single construction to define different hierarchies, thus for a single situation to simultaneously carry conflicting grammatical markers, one marking the situation as Direct and the other as Inverse.

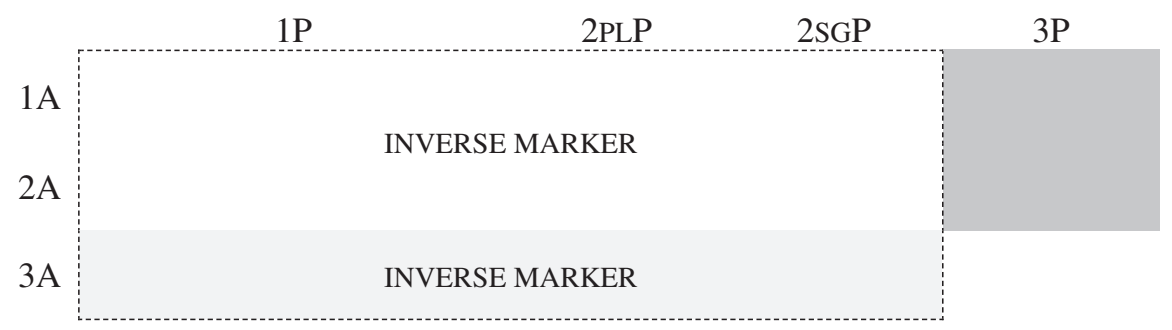

Figure 16: The modern direction-marking domains of SLP Huastec.

In order to identify the source of the hierarchical distribution of these proclitics, and also the direction marker t- "INVERSE", we must begin with the indexation patterns of the other Mayan languages. In Proto-Mayan (and in nearly all modern Mayan inflectional systems), there are two sets of morphemes: Set A forms uniquely mark the A (ergative), whereas Set B forms mark the absolutive. In transitive clauses, both markers co-occur, as modeled in Figure 17. This is a straightforward ergative-absolutive system, with every argument marked and therefore no trace of hierarchical indexation. Note, however, that because the third person Set B form is null, we symbolize this in Figure 17 as $\varnothing$ - rather than as B3, and we point out that this creates the necessary prior condition for a reanalysis of the referential null form as simply the absence of third person $\mathrm{P}$ indexation (cf. the Cariban and Tupí-Guaraní cases from Section 2.3.1).

The earliest attestation of Huastec is from the colonial records in Tapia Zenteno (1767), a version of the language that Zavala (1994) refers to as Colonial (COL) Huastec. In COL Huastec, the ergative-absolutive indices are supplemented in the Local and Inverse quadrants with an extra marker, ta- (cf. Table 5, from Zavala 1994: 68), which occurs in every scenario where the goal of the action is 
directed at a first or second person P. Zavala also notes the phonological similarity between this $t a$ - prefix and a neutral locative preposition $t a$, and lists previous authors who have explicitly linked the two. As such, in both distribution and probable morphological source, the COL Huastec $t a$ - prefix looks very much like a case of a deictic marker that has been reanalyzed as a direction marker, as described in Section 2.2. This is already precisely the pattern identified for the $t$ - "INVERSE" prefix in SLP Huastec, already modeled in Figure 17, so we do not model it again.

\begin{tabular}{llccc}
\hline & $1 \mathrm{P}$ & $2 \mathrm{P}$ & $3 \mathrm{P}$ \\
\cline { 2 - 4 } 1A & & $\mathrm{B} 2-\mathrm{A} 1$ & $\emptyset-\mathrm{A} 1$ \\
2A & $\mathrm{B} 1-\mathrm{A} 2$ & & $\emptyset$-A2 \\
& $\mathrm{B} 1-\mathrm{A} 3$ & $\mathrm{~B} 2-\mathrm{A} 3$ & $\emptyset-\mathrm{A} 3$ \\
\hline
\end{tabular}

Figure 17: Proto-Mayan ergative-absolutive indexation.

Table 5: Distribution of the Colonial Huastec proclitics.

\begin{tabular}{llllll}
\hline & 1PLP & 2sGP & 2PLP & 1sGP & 3P \\
\hline 1sGA & & $t a-t-u$ & $t a-x-u$ & & $\varnothing-u$ \\
1PLA & & $t a-t-i$ & $t a-x-i$ & & $\varnothing-i$ \\
$2 \mathrm{sGA}$ & $t a-w a$ & & & $t a-n-a$ & $\varnothing-a$ \\
$2 \mathrm{PLA}$ & $t a-w a$ & & & --- & $\emptyset-a$ \\
$3 \mathrm{~A}$ & $t a-w a$ & $t-i$ & $t-i-$ & $t a-n-i n$ & $\varnothing-i n$ \\
& & & & & \\
$\mathrm{~S}$ & $w a / u$ & $i t$ & $i x$ & in & $\varnothing / u$ \\
\hline
\end{tabular}

However, note that the argument marking in Colonial Huastec is not yet so radically changed from the other Mayan languages: both ergative and absolutive are still marked via the proclitics for most combinations of person. The exception is that the third person Set A proclitic is already lost in most of the Inverse quadrant, being retained only when $3 \rightarrow$ 1sG; similarly, the second person Set A proclitic is lost when $2 \rightarrow 1$ PL. These changes indicate the birth of a limited indexation hierarchy, in which $1 \mathrm{PL}>2>1 \mathrm{SG}=3$. These patterns are modeled in Figure 18, with the row of $\mathrm{P}$ arguments sorted according to this hierarchy. We draw the even dashed line indicating Inverse indexation around the situations that are marked only by a single $\mathrm{P}$ proclitic, and once again, we indicate that the third person Set B marker is the null form Ø- “3B” rather than a "DIRECT” morpheme (i. e., truly indicating only the P). 


\begin{tabular}{|c|c|c|c|c|}
\hline & 1PLP (B) & $2 \mathrm{P}(\mathrm{B})$ & 1SGP (B) & $3 \mathrm{P}(\mathrm{B}=\varnothing)$ \\
\hline $1 \mathrm{~A}$ & & $t a-\mathrm{B} 2-\mathrm{A} 1$ & & $\varnothing-\mathrm{A} 1$ \\
\hline $2 \mathrm{~A}$ & $t a-\mathrm{B} 1$ & & $t a-\mathrm{B} 1-\mathrm{A} 2$ & Ø-А2 \\
\hline $3 \mathrm{~A}$ & $t a-\mathrm{B} 1$ & $t a-\mathrm{B} 2$ & $t a-\mathrm{B} 1-\mathrm{A} 3$ & $\varnothing-A 3$ \\
\hline
\end{tabular}

Figure 18: Colonial Huastec: Direction marking already in place, limited hierarchical indexation.

However, given that the third person Set A form has disappeared in most environments, one might question whether this null form is, in fact, (still) real in the minds of the speakers. If we were to analyze it as absent already at this stage of the language, then a hierarchical system would be mostly in place, one that resembles the Quileute patterns modeled in Figure 6 above, with only the SAP participant marked in the Direct quadrant and in most of the Inverse quadrant, but both SAP participants marked in most of the Local quadrant.

The changes that characterize the transition from COL (as shown in Table 5 and Figure 18) to modern SLP (as shown in Table 4, Figure 15 above) are now clear. For expository convenience, we enumerate these changes, but this is not to be (mis)understood as a possible claim about the sequence in which the changes took place - in most cases, we have neither empirical evidence nor any theoretical basis to make claims about the order of these changes.

1. The COL prefix ta- "INVERSE" reduces to a single consonant, the SLP t"INVERSE"; as its paradigmatic distribution does not change, this in itself has no effect on any hierarchical patterns.

2. In the situation where $3 \rightarrow 1$, the third person Set A proclitic still seen in COL disappears in SLP, leaving the first person Set B proclitic as the only form. This moves first person above third person in the hierarchy, and makes the entire Inverse quadrant consistent in using only the SAP Set B proclitic.

3. At this point, we feel justified in joining Zavala to analyze the Direct and Nonlocal scenarios as no longer marking the 3P; that is, the third person zero Set B proclitic that SLP inherited from Proto-Mayan is arguably reanalyzed as simply the absence of a marker for 3P. This would make the Direct and Inverse quadrants parallel, both characterized by the absence of third person indexation. Given that the Nonlocal quadrant also shared the null third person Set B proclitic, it now shares the Direct pattern, in that it marks only the A argument.

4. The Local quadrant undergoes a major reorganization:

a. In the $2 \rightarrow 1 \mathrm{sg}$ situation, the COL second person Set A proclitic is lost, leaving in SLP only the Set B proclitic that indicates 1P. Combined with change (2) above, this has the effect of changing the hierarchy 
dramatically, so that first person singular jumps from its place with third person at bottom of the COL hierarchy to join 1PL at the top of the SLP hierarchy.

b. In the $1 \mathrm{PL} \rightarrow 2$ situation, the $1 \mathrm{SG}$ Set A proclitic replaces the 1PL Set A proclitic, collapsing the morphological distinction between $1 \mathrm{sg} \rightarrow 2$ and $1 \mathrm{PL} \rightarrow 2$. We presume that this change happened before the distinct changes $c$ and $d$, because it is found independently of the changes in $\mathrm{c}$ and $\mathrm{d}$. This change has no effect on the hierarchy, although there is a perspective from which it could be seen as another piece of evidence that 1SG and 1PL are identical in terms of the SLP hierarchy.

c. Both $1 \rightarrow 2 \mathrm{sg}$ situations lose the 2sG Set B proclitic. This has the effect of putting first person above 2sG in the hierarchy in both halves of the Local domain.

d. Both $1 \rightarrow 2 \mathrm{PL}$ situations retain the option of marking the 2PLP via the Set $\mathrm{B}$ proclitic, leaving this as the only situation where the system allows speakers to mark both participants. The optional retention of this 2PL Set B proclitic allows us to say that 2PL is above 2sG in the hierarchy, since in all interactions with first person, the marker of 2sG is completely lost.

We can now summarize the creation of the hierarchical grammatical patterns in SLP. The direction marker is an old deictic marker that becomes obligatory in all situations where action is directed at a speech act participant. Already in COL, it shows the expected pattern, marking all Inverse and Local situations, and this does not change in SLP. A hierarchical system of person indexation in the Direct quadrant was already incipient, in that the $3 \mathrm{P}$ marker reconstructs to Proto Mayan as a null form; hierarchical indexation is created in the Inverse quadrant by the loss of the prior $3 \mathrm{~A}$ marker. The changes in the Local quadrant mostly came later (post-COL), and can be simply characterized as the progressive loss of second person proclitics, leaving behind only the first person forms. Once again, these sources do not give rise to either Obviative case marking or to a Nonlocal direct-inverse alternation. ${ }^{12}$

12 Kondić (2012) suggests that these changes in Huastec were likely a consequence of contact between that language, which has migrated quite far to the north from the main body of Mayan languages, and languages of the intervening Mixe-Zoquean family, which all have hierarchical systems. While such a shift would make sense given a high degree of bilingualism, that contact probably took place prior to Colonial Huastec - therefore not having been a factor in the completion of the further changes (especially (2) and (4)) that have taken place in recorded history. 


\subsubsection{Second-position clitics > hierarchical verbal indexation in Reyesano}

The synchronic verbal system of Reyesano (Tacanan; Bolivia) has been described in Guillaume (2009), who carefully lays out the hierarchical pattern: transitive verbs may bear a single person prefix that refers to first or second person, in the singular or plural, with no formal distinction based on the syntactic role of that SAP participant: $m$ - "1sG", $k$ - "1PL", mi- "2sG", and mik"2PL". When the A is third person (singular or plural), the verb also bears the suffix - $t a$ " $3 \mathrm{~A}$ ". When there are two SAP participants, the prefix always indicates second person, thereby allowing us to posit the following hierarchy for personal indexation: $2>1>3$. The combination of SAP prefixes and the $3 \mathrm{~A}$ suffix occur in paradigmatic combinations as in Table 6.

Table 6: Person-marking paradigm for Reyesano (Tacanan; Bolivia).

\begin{tabular}{|c|c|c|c|c|c|}
\hline & $2 s G P$ & 2PLP & $1 \mathrm{sGP}$ & 1PLP & $3 P$ \\
\hline $2 \mathrm{sGA}$ & & & $m i-$ & $m i-$ & mi- \\
\hline $2 \mathrm{PLA}$ & & & (unattested) & (unattested) & mik- \\
\hline $1 \mathrm{sGA}$ & $m i-$ & (unattested) & & & $m-$ \\
\hline 1PLA & (unattested) & (unattested) & & & $k-$ \\
\hline $3 A$ & $m i-\ldots-t a$ & mik-...-ta & $m-\ldots-t a$ & $k-\ldots-t a$ & $-t a$ \\
\hline S & $m i-$ & mik- & $m$ & k- & $-t a^{a}$ \\
\hline
\end{tabular}

${ }^{\mathrm{a}}$ For intransitive verbs, -ta is only $3 \mathrm{PLS}$, leaving $3 \mathrm{sGS}$ unmarked.

The inclusion of this system in the section describing cases of the $\varnothing$ - " 3 " source of hierarchy is motivated by the absence of third person prefixes, even in the Nonlocal quadrant. However, it occurs in its own subsection because verbs do have a clear marker of third person, just in a different morphological slot on the verb, as a suffix. Interestingly, given that there is no morphological marker of

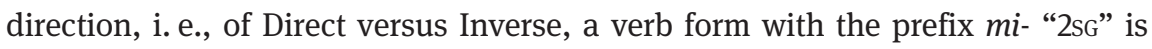
multiply ambiguous, between the three ambiguous direct readings of $2 \mathrm{sG} \rightarrow 1 \mathrm{sG} /$ $1 \mathrm{PL} / 3$ and the single Inverse reading $1 \rightarrow 2 \mathrm{sG}$; when $3 \rightarrow 2 \mathrm{sG}$ we again have the sole prefix mi- "2sG", however it is not ambiguous with the other four cases because of the presence of the suffix - $t a$ " $3 \mathrm{~A}$ ".

Guillaume (2009: 43-46) considers an alternative analyses, in which the suffix - $t a$ is not a person marker, but is instead a marker of Inverse direction: in favor of this analysis is that it puts the person markers all into the same paradigm, adding Ø- "3" to the set of prefixes, and that it removes from the analysis the only person marker that specifically marks a grammatical role, -ta " $3 \mathrm{~A}$ ", leaving role 
information to be inferred from the presence or absence of the Inverse marker, -ta. However, he discards this analysis for three reasons: (i) it requires the postulation of a covert morpheme, Ø- "3", on all Nonlocal verbs, as opposed to the more straightforward overt analysis of - $t a$ as " $3 \mathrm{~A}$ "; (ii) in the Nonlocal domain, there is no Inverse-Direct alternation, as - $t a$ must occur every time there is a $3 \mathrm{~A}$ in the scenario; and (iii) the form - $t a$ is clearly a person marker in intransitive clauses, where it refers to 3PLS. In addition, the form $t a$ is also an independent third person genitive pronoun in Reyesano and in comparative data he finds multiple cases in which the form ta occurs in other Tacanan languages with a third person meaning, either in paradigms or in free pronouns (often in combination with other material); cf. also Guillaume 2011, in which he reconstructs *-ta "3PLA" to Proto-Tacanan. To these arguments, we would add one more: in the Local quadrant, the only morphological marker on the verb is mi- "2sG", creating the ambiguity (discussed above) between $1 \rightarrow 2 \mathrm{sg}$ and $2 \mathrm{sG} \rightarrow 1$; were one to analyze the suffix - $t a$ as an Inverse marker, then one would have to explain why it does not occur in the Local Inverse situation, i. e., $1 \rightarrow 2 \mathrm{sG}$, where it would serve a useful disambiguation function. ${ }^{13}$

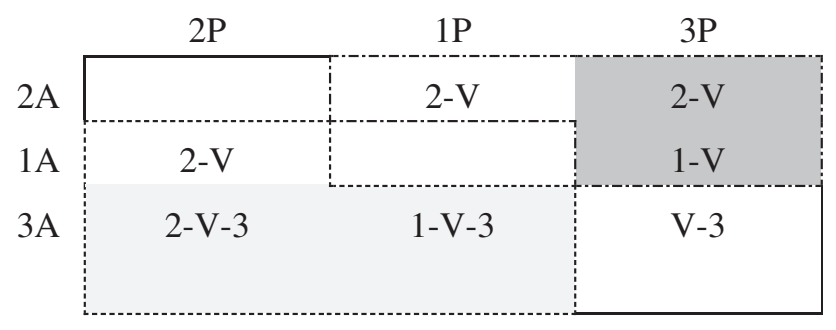

Figure 19: Modeling personal indexation in Reyesano: $2>1>3$.

We model the Reyesano hierarchical patterns in Figure 19. Although the verbal prefixes do not alter their form based on role, we can identify the semantic pattern that in the Direct quadrant, the referent of these prefixes is the actor and in the Inverse quadrant, the referent of these prefixes is the undergoer (with the actor explicitly indexed by $-t a$ " $3 \mathrm{~A}$ "). For all attested situations in the Local

13 Although we agree with Guillaume that the " $3 \mathrm{~A}$ " analysis is superior, we do point out that were it to also occur on the $1 \rightarrow$ 2sG verb, this pattern would make the "INVERSE" analysis superior, and given the comparative evidence that the source of the form is as a third person A marker, we would then be able to add a $3 \mathrm{~A}$ morpheme to the list of source forms for markers of inverse direction. However, a 3A source for a direction morpheme is (so far) unattested, and while the Reyesano case does show a potential scenario where it could happen, it remains hypothetical. 
quadrant, the verb takes only a second person prefix, so we extend the Direct box to include $2 \rightarrow 1$ because the indexed second person is the agent and we extend the Inverse box to include $1 \rightarrow 2$ because the indexed second person is the patient. By this metric, the Nonlocal quadrant does not join either direct or Inverse, as it has no verbal prefixes to distinguish it. One could imagine analyzing it as in alignment with Direct, in that the only morphological person marker refers to the actor, or in alignment with Inverse, in that all of the forms in the Inverse quadrant show the same $3 \mathrm{~A}$ suffix. ${ }^{14}$

We turn now to the diachronic question: what source gives rise to the Reyesano Hierarchical indexation? In three works comparing the grammar of main clauses in Tacanan languages, Guillaume (2011, 2014, forthcoming) makes a compelling case that hierarchical indexation is an innovation in Reyesano, which is also the only language in the family that shows no trace of the ergative case-marker found in the rest of the Tacanan languages. Four of the five languages have the suffix $-t a$ " $3 A$ " on verbs and the cognate suffix in the fifth, Cavineña, is a passive verbal suffix (Guillaume 2011). Thus, the suffix - $t a$ " $3 \mathrm{~A}$ "15 reconstructs easily with this function, so its presence requires no additional historical explanation.

The changes that do require explanation are the apparent complete loss in Reyesano of the family-wide ergative case-marker, plus the innovation of the hierarchical verbal prefixes. Given that neither hierarchical indexation nor neutral case marking are found in any other language in the Tacanan family, one would like to link the two and suggest that this must be either a case of recent innovation or retention of an older construction lost in the rest of the family. However, Guillaume (forthcoming) argues that these are, in fact, unrelated individual changes that happened to co-occur in Reyesano. The loss of the ergative case-marker appears to be underway also in Tacana, another language within the sub-branch of Tacanan that contains Reyesano, so the lack of case marking in Reyesano seems merely to be the natural conclusion to this process of loss (see also Guillaume 2014).

For our purposes, the crucial pattern to be explained is the genesis of a set of hierarchical verbal prefixes, especially given that no other language in the family has verbal indexation beyond the " $3 \mathrm{~A}$ " suffix. The first task is identifying forms that are cognate to the forms of these person-markers, and the

14 However, this would complicate inclusion of the $1 \rightarrow 2$ situation in the INVERSE box, as it does not share the -ta suffix.

15 Actually, Guillaume (2011a) reconstructs *-ta "3PLA"; for our argument, the number distinction is not germane. 
second is to figure out how they could have changed from whatever they were into the verbal prefixes that they are today. Guillaume (forthcoming) shows that several of the Reyesano personal prefixes are cognate to SAP free pronouns and, crucially, to reduced forms of these pronouns that are found as second position clitics in at least two other languages of the family (Cavineña and Ese Ejja). Based on this comparative evidence, it seems reasonable to posit that the ancestor to Reyesano also had these forms as SAP second position clitics. ${ }^{16}$ Guillaume then posits that, perhaps influenced by adjacent Arawakan languages, Reyesano speakers reanalyzed these second position clitics as the attested SAP verbal prefixes. Note that there appears to be no evidence for the creation of the two patterns within a single system via reanalysis of, for example, subordinate constructions. ${ }^{17}$

While we find this scenario convincing, it does not, strictly speaking, solve our problem. That is, while Guillaume's reconstruction does provide a source for the morphological forms that become the prefixes and a mechanism by which they became prefixes, there are many languages in the world that have developed prefixes from pronouns/clitics without developing similar hierarchical paradigms. Looking more closely at the source, however, we see that the hierarchical pattern for third person interacting with SAP reconstructs almost automatically: given the presence of the third person suffix on the verb, there was no functional pressure to produce a second position clitic to further index anaphoric third person participants. As such, the absence of a third person prefix would follow mechanically from the absence of a third person clitic, making the development of SAP indexation on the Reyesano verb simply a more complex version of the null third person sources documented earlier in this section.

However, the source does not give us an automatic reconstruction of the hierarchical preference for second person over first person. That is, we know that the original set of second position clitics had forms referring to both first and second persons, so logically speaking, when $1 \rightarrow 2$ and $2 \rightarrow 1$, both first and second position clitics could have occurred in second position. While there are important differences, ${ }^{18}$ in Tacanan language Cavineña (as described in Guillaume 2010: 105), both first and second person clitics do occur in both Local scenarios with

16 Note that in Cavineña, the one language in the family that has reanalyzed the third person verbal suffix as a marker of voice, it is perhaps not surprising to find that the set of second position clitics has been supplemented with third person forms, cf. Guillaume (2010).

17 To fully rule out a role for reanalysis in the Reyesano innovations, it would be nice to also see that Reyesano TAM suffixes are cognate with those found elsewhere in the family.

18 For example, A clitics in Cavineña bear ergative case. 
their order determined by the hierarchy $1>2>3$ : the highest-ranking form always occurs last. As such, for both Local scenarios in Cavineña, $1 \rightarrow 2$ and $2 \rightarrow 1$, the order of clitics is always $=2=1$. Another potentially relevant pattern in Cavineña is that the final syllable of the second position clitic cluster deletes when followed by another constituent (for example, the verb) - this leads to a fairly frequent pattern in which the first person clitic is deleted entirely, again regardless of grammatical role. If we assume that these two patterns $(=2=1$ order and final syllable deletion) from Cavineña held also in the ancestor to Reyesano, then we would have a situation in which a following verb would cause the first person clitic to be deleted, leaving only the second person clitic available to become the verbal prefix, regardless of grammatical role.

While this seems to provide a neat solution to the problem in Local scenarios, so general a mechanism as "final clitic deletion" would actually create problems in cases where SAP clitics would have been final, but were not deleted. For example, the first person clitic would also have been final preceding the verb in both intransitive clauses and when $1 \rightarrow 3$ and $3 \rightarrow 1$, yet it survived to become a verbal prefix. Similarly, the second person clitic would have been final in intransitive clauses and when $2 \rightarrow 3$ and $3 \rightarrow 2$, yet it, also, was not deleted. We might speculate that the final clitic was only deleted when part of a sequence of person clitics, but since this would limit the phenomenon to $1 \rightarrow 2$ and $2 \rightarrow 1$, it seems almost as ad hoc as simply stipulating that speakers decided to rank second person above first, and thus deleted the first person clitic for hierarchical reasons (precisely the type of teleological argument we are trying to avoid here).

To summarize what we know about this addition to our list of source constructions, it works in a way quite similar to the null third person source in that the hierarchical pattern in indexation reflects the absence of a third person form in the source material, this time not because third person is simply a null form, but because it is already marked elsewhere, via a verbal suffix. The source provides no direction marker (although the 3A suffix does come tantalizingly close), no Direct-Inverse alternation in the Nonlocal quadrant, and no Obviative case-marker - in fact, the reconstructible ergative casemarker, which might reasonably have been pressed into service for this function, was instead lost altogether, thus providing no evidence for diachronic pressure from some cognitive instantiation in speakers of "the hierarchy". Further, if our hypothesis is correct, then the Cavineña clitic ordering hierarchy of $=3<=2<=1$ plus final clitic deletion would mechanically give rise to a change in the hierarchy, from $1>2>3$ to $2>1>3$, making the hierarchy itself appear more an epiphenomenon of linguistic analysis than a description of the cognitive reality of speakers. 


\subsection{Two cleft constructions > a Direct-Inverse alternation in Movima}

The previous sections treated sources of hierarchical grammar for which we have multiple examples, and so each received its own section. In this section, we describe a source for which we have only one example. The language that provides these examples is Movima, an unclassified language spoken by some 1,000 people (mostly elders) in Bolivia. The grammar of main clauses in Movima has been the subject of multiple studies by Haude (especially 2006, 2009, 2010); the analysis presented here is more fully developed in Gildea and Haude (2011), for which Haude (p.c.) provided all the Movima examples presented here. In Movima main clauses, there is neither case-marking nor verbal indexation to distinguish argument structure, but syntactic position and certain properties of cliticization allow us to distinguish what Haude (2010) calls the "internal argument" (the Proximate, or most hierarchically prominent argument of a transitive clause) from the "external argument" (the S of an intransitive clause or the Obviative, or less hierarchically prominent argument of a transitive clause). Recall (from Section 1) that the prototypical use of the terms "Proximate" and "Obviative" is to mark morphologically flagged arguments: the Proximate is the (usually unmarked) higher-ranked argument, whereas the Obviative is marked on the lower-ranked argument. In Movima, Proximate still refers to the higherranked and Obviative to the lower-ranked argument, but instead of being marked via morphological flagging, the relative ranking of the arguments is marked via syntactic position. As such, basic constituent order in Movima is not easily stated in terms of subject and object: it is rather Obviative [V= Proximate]. Table 7 gives a fuller list of properties that distinguish Proximate from Obviative, which include (i) syntactic position, (ii) obligatoriness, (iii) the units within the DP that cliticize to the preceding predicate, ${ }^{19}$ and (iv) the distinct phonological properties of "internal" versus "external" cliticization.

Using these properties, it is always possible to identify the referent associated with each argument type. For intransitive clauses, a single unmarked DP must be in the $S$ role. If the $S$ is a DP in post-predicate position, its initial element (the determiner)

19 Note that Haude (2010) does not use part of speech terms like "noun" or "verb", nor does she invoke the corresponding phrasal categories "NP" and "VP". All referring expressions must have a determiner, which Haude (2010) argues is the head of a Determiner Phrase (DP), analogous to a noun phrase in languages with a clearer noun-verb distinction. Nearly any word that occurs outside of a DP is interpreted as a predicate, labeled PRED in Table 7 and subsequent schematic diagrams. 
Table 7: Formal properties of argument encoding in Movima.

\begin{tabular}{ll}
\hline Internal (Proximate) & External (OBVIATIVE/ S) \\
\hline Rigid position: [PRED = PROX] & May precede or follow [PRED INTR $_{\text {O PRED = PROX] }}$ \\
Obligatory & Not obligatory \\
Cliticize pronouns and articles & Cliticize only pronouns \\
(=): stress shift, epenthetic LV /a/ & $\begin{array}{l}\text { (-): resyllabification, } \\
\end{array}$ \\
& no stress shift, no epenthetic LV /a/ \\
\hline
\end{tabular}

does not cliticize (4a), whereas if it is a pronoun in post-predicate pronoun, it cliticizes according to the pattern of external cliticization (indicated orthographically as --).
a. V
[ $\quad$ S
$\mathrm{S} \quad]$
joy-chet is juyeni n-as lo:los
gO-REFL ART.PL person OBL-ART.N village
“The people went to the village." [tx]

b. V--s

$$
\begin{aligned}
& \text { kuyna:nak--i’ne } \\
& \text { play--3F } \\
& \text { "She plays.” [tx] }
\end{aligned}
$$

With transitive predicates, there is both an internal, or Proximate argument, and an external, or Obviative argument. When the Proximate argument is the actor, as in (5a)-(5b), the transitive predicate word occurs in its Direct form, marked by either the infix $\langle a\rangle$ or the suffix -na "Direct". In (5a), the article is of the Proximate DP is pa:ko "the dogs" cliticizes to the predicate according to the pattern of internal cliticization (marked orthographically as =), whereas the Obviative DP os rulrul "the jaguar" follows with no cliticization. In (5b), the absence of an explicit form marks the first person Proximate, which is followed by the non-cliticized Obviative DP is chujat-di "motacú nuts". Because the transitive predicates in (5a)-(5b) occur in their Direct forms $(<a>$ "Direct" in (5a), -na "Direct" in (5b)), the listener understands that the Proximate argument is the actor and the Obviative argument is the undergoer.

$$
\begin{aligned}
& \text { a. } \mathrm{V}=\mathrm{PROX} \quad \mathrm{OBV} \\
& \text { man<a>ye = is pa:ko os rulrul } \\
& \text { meet }<\text { DIR }>=\text { ART.PL dog ART.N.PST jaguar } \\
& \text { "The dogs found a jaguar." [tx] }
\end{aligned}
$$


b. $\mathrm{V}=\mathrm{PROX} \quad \mathrm{OBV}$
jiwa-te:-na $=\underline{\emptyset}$ is chujat-di
come-CO-DIR =1SG ART.PL motacú-seed
"I brought motacú nuts." [tx]

When the Proximate argument is the undergoer, the transitive predicate word must take the suffix -kay "InVERSE" (6a)-(6b). In (6a), the Proximate pronoun us "him" cliticizes to the predicate using the patterns of internal cliticization, while the Obviative DP os pa:ko "the dog”, follows without cliticization. In (6b), the Proximate pronoun 'ne "her" cliticizes to the predicate using the patterns of internal cliticization, whereas the Obviative DP as jidan-wa= 'ne "her being full" follows without cliticization. Because the transitive predicates in (6a)-(6b) bear the suffix -kay “INVERSE”, the listener understands that the Proximate argument is the undergoer and the Obviative argument is the actor.

a.

$$
\mathrm{V}=\text { PROX }
$$

OBV

jayte os pa:ko, kajte-kay- $a=\underline{\text { US }}$ os pa:ko

then ART.N.PST dog go.to.meet-INV-LV =3M.AB ART.N.PST dog

"Then the dog, the dog went to meet him." [tx]

b. $\mathrm{V}[=\mathrm{PROX}]$

OBV

$$
\begin{aligned}
& \text { joro-poj-kay-a ='ne as jidan-wa='ne i'nes Lus } \\
& \text { sleep-CAUS-INV-LV }=3 \text { F ART.N be.full-NMLZ }=3 \text { F ART.F Luz } \\
& \text { "Her being full has made her, Luz (name of a dog), fall asleep.” [tx] }
\end{aligned}
$$

So far, we have seen no evidence for hierarchical patterns in the grammar of Movima, just labels for core arguments of the predicate (Proximate versus Obviative) and direction morphemes on those predicates (Direct versus Inverse) that are drawn from the descriptive tradition of Algonquian languages, where the first Direct-Inverse systems were described and labeled. In multiple works, Haude has documented that the participant that will be encoded as the Proximate argument is always the highest on the hierarchy 1>2>3; Haude (2009: 520) also affirms the existence of a categorical hierarchy in which 3 human $>3$ animate $>3$ inanimate. However Haude (2010: 301) weakens this, showing that while a higher ranked actor participant is always coded as the Proximate argument, and thereby conditions the Direct form of the verb, sometimes when a human is the undergoer and an animate actor has discourse topicality, the lower ranked actor may be coded as Proximate, producing the option of a Direct verb in what should be a purely Inverse situation. In Figure 20, we model this almost perfect division of the four quadrants into two domains coded exclusively with Direct versus Inverse 


\begin{tabular}{|c|c|c|c|c|c|}
\hline & $1 \mathrm{P}$ & $2 \mathrm{P}$ & 3HUMANP & 3ANIMATEA & 3INANIMATEA \\
\hline $1 \mathrm{~A}$ & & DIRECT & DIRECT & DIRECT & DIRECT \\
\hline $2 \mathrm{~A}$ & INVERSE & & DIRECT & DIRECT & DIRECT \\
\hline 3HUMANA & INVERSE & INVERSE & DIRECT/INVERSE & DIRECT & DIRECT \\
\hline 3ANIMATEA & INVERSE & INVERSE & DIRECT/INVERSE & DIRECT/INVERSE & DIRECT \\
\hline 3INANIMATEA & INVERSE & INVERSE & INVERSE & INVERSE & DIRECT/INVERSE \\
\hline
\end{tabular}

Figure 20: Modeling direction marking in Movima.

grammar, leaving speakers a choice of construction only in the situations where both third person arguments are equal in status (i. e., 3 human $\rightarrow 3$ human, 3 animate $\rightarrow 3$ animate, and 3 inanimate $\rightarrow 3$ inanimate) and in the unexpected case where 3 animate $\rightarrow 3$ human (cf. Haude 2012).

Reconstructing the source of this pattern is complicated, given the absence of related languages in which to search for cognate constructions. However, based on Haude (2010), Gildea and Haude (2011) identified internal cognates for both the syntactic properties of structure and the direction morphemes themselves in cleft constructions. Before showing the clefts, we first describe the relative clauses (nominalizations) that are at the heart of clefts. In brief, adding a determiner to an intransitive verb derives a word that refers to the notional $\mathrm{S}$ of that predicate, like is $j i<w a:>w a$ "those who came" in (7). To refer to the notional actor of a transitive verb, one adds a determiner to the Inverse form of the transitive verb, as in os rey joyłekaya =us "one ${ }_{i}$ who took him with (him ${ }_{i}$ )" in (8), whereas to refer to the notional undergoer, one adds a determiner to the Direct form of the transitive verb, as in kis payabija $=n$ "the one we make" in (9).

(7) PRED [DET $\left.\mathrm{V}_{\text {INTR }} \quad\right]_{\mathrm{DP}}$

treynta is $\quad j i<w a:>w a \quad$ ADV ney

thirty ART.PL come<MID> here

"Thirty (people) came here." (lit. "The comers here (are) thirty")

CCT_120907_1013

(8) $\left[\mathrm{V}_{\text {INTR }}\right]_{\text {PRED }}[\mathrm{DET} \text { MOD } \mathrm{V}=\mathrm{INV}=\mathrm{PROX} \quad]_{\mathrm{DP}}$

ji<wa:>wa os rey joy-łe-kay-a =us ney

come<MID> ART.N.PST MOD go-CO-INV-LV = 3M.AB here

"[Someone who took him with him] came here."

(lit. "His taker came here.”)

(CCT_120907_1 100) 
(9) $\quad[\mathrm{V}-\mathrm{INV}=\mathrm{PROX}]_{\mathrm{PRED}} \quad[\mathrm{DET}$

julra-kay-a $=n \quad$ kis, eney, pay-a-bij-a $=\boldsymbol{n}$

win.over-INV-LV=2 ART.PL.AB (filler) smear-DIR-CL:POT-LV=2

"[The pottery we (incl.) make] wins over us (i.e., it dries too quickly when it's sunny).”

(lit. "our makee (by smearing) defeats us.”)

(CCT_120907_1 022)

Grammatically, these last two constructions are identical to possessed nouns in predicate position, as seen in (10)-(12). First, note that equative and proper inclusion constructions in Movima do not utilize a copular element, but merely juxtapose the two referring expressions to be equated. For unpossessed referring expressions, the order may be either $\mathrm{S}$ pred or pred $\mathrm{S}$, whereas when the predicate is a possessed referring expression, only the order S pred is admissible (cf. the disallowed pred S order in (10b)). In (11), there are two such referring expressions as predicates, both possessed by pronominal clitics that are identical in both structural position and cliticization properties to Proximate arguments of transitive predicates: first alle='ne "her relative" and second alle $=\varnothing$ "my relative". In (12), the referring expression in predicate position is wa:kawandi "ranch", and it is possessed by the DP is Nasis "the Nacif (family)"; once again, syntactic position and internal cliticization of the determiner makes the grammatical properties of the possessor identical to those of the Proximate argument of a transitive predicate.

(10) a. asko pa:ko=us

PRO.N.AB dog=3M.AB

"That's his dog."

b. ${ }^{\star} \boldsymbol{p a}: k o=u s--k a s$

dog=3M.AB--OBV:3N.AB

("It is his dog.")

(11) $[\mathrm{PRO}]_{\mathrm{OBV}}[\mathrm{RP}=\text { POSSESSOR }]_{\mathrm{PRED}}[\mathrm{PRO}]_{\mathrm{OBV}}[\mathrm{RP}=\mathrm{POSSESSOR}]_{\mathrm{PRED}}$

inta alle $=$ 'ne, it ..., i'ne $=\$$ alle $=\varnothing$

$\mathrm{PRO} .1 \mathrm{SG}$ relative $=3 \mathrm{~F} \quad$ 1INTR $\quad \mathrm{PRO} . \mathrm{F}=1$ relative $=1 \mathrm{SG}$

"I am her relative, I ..., she is my relative."

(ERM_140806_2 217) 
(12) $[\mathrm{RP}]$ [demonstrative $]\left[\mathrm{RP}=[\text { possessor } \mathrm{RP}]_{\mathrm{DP}}\right]_{\mathrm{PRED}}$

Esteri:na, a'ko wa:ka-wandi $=$ is Nasis

(proper name) PRO.N cow-INSTR:CL:house=ART.PL (proper name)

"Esterina, that's the ranch of the Nacif (family)."

(ATL_230806 397)

While we cannot recapitulate their extensive argumentation here, we follow Gildea and Haude's (2011) conclusion, that the cleft constructions in (13)-(14) were the source of the modern hierarchical verbal system in Movima. Simple examples of the source construction, all of which come from discourse, show the combination of form and denotational meaning already in the source, making these constructions easy to reanalyze into the modern verbal constructions. The undergoer cleft in (13) begins with the S pronoun asko "that", followed by the possessed noun jamate = 'ne "her hangee"; the actor cleft in (14) begins with the same S pronoun asko "that", followed by the possessed noun tetpojkaya "scarer" and its possessor, the DP is we:ye "the ox".

(13) $\left.\mathrm{S}_{\mathrm{NV}} \quad[\mathrm{RE}=\mathrm{psr}]\right]_{\mathrm{PRED}}$

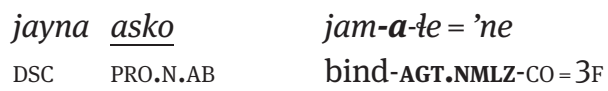

"That is her hung-up (one) then." > Direct "That one she hangs up then."

(14)

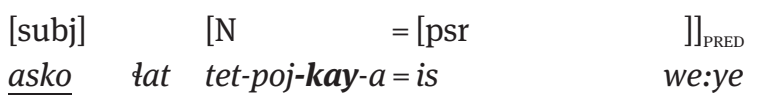

PRO.N.AB EVID scared-CAUS-PAT.NMLZ-LV = ART.PL OX

"That, they say, was the scarer of the ox." > Inverse "That, they say, scared the ox."

Given that these two cleft constructions are virtually identical to, respectively, the modern Direct and Inverse main clauses, one must next argue for the direction of change: did the clefts give rise to the main clause verbal constructions, the main clause verbal constructions to the clefts, or are clefts and main clause verbal constructions sisters, each independently descended from some third construction that is no longer attested? Gildea and Haude (2011) argue for the first option, citing multiple examples in the literature of relative clauses in cleft constructions > focus constructions > obligatory main clause grammar: examples of the change from clefts to main clause focus constructions are found in Celtic (Harris and Campbell 1995: 157) and Japanese (Iwasaki 1993), and they go on to become obligatory (i. e., the only forms used) in main clauses 
in Rendille (East Cushitic, Kenya; Heine and Reh 1984: 165-169). In contrast, they encountered no cases of the change from obligatory main clause construction > focus construction > relative clauses in clefts, and as such, the only reasonable reconstruction is that a source cleft construction has continued to exist as a cleft in modern Movima while the same source has also been reanalyzed, presumably first as a focus construction and then on to become, like in Rendille, the only construction that codes main clause eventive predicates.

Now that we understand the origins of the grammar of Movima direct and inverse clauses, we can return to the question of the genesis of the hierarchical restrictions on selection of which argument will be Proximate and which Obviative. We begin with the observation that, as seen in (11) above, there is no hierarchical selectional restriction on the possessor of a referring phrase predicate: both "I am her relative" (S outranks possessor) and "she is my relative” (possessor outranks S) occur freely. It stands to reason that the source cleft construction would have been similarly free, with the possibility of examples like "I am her seen.Direct one" and "I am her seer.INVERSE". With regard to this possibility, in her discussion of how information structure effects like focus might affect the hierarchy, Haude (2012: 178) gives all six of the examples from her corpus in which a focus construction (which looks like our posited etymological source cleft) brings the higher-ranked undergoer to S position and leaves a lower-ranked actor to serve as the internal argument (which we would certainly analyze diachronically, and perhaps still synchronically, as the possessor of the verbal noun that is the predicate in a cleft construction). ${ }^{20}$ Although Haude reports finding a handful of examples of the type "I am her seen.DIRECT one", she has not encountered any examples of the type "I am her seer.INVERSE”, and reports that her attempts to elicit one were unsuccessful.

$$
\begin{array}{llll}
\text { jayna } & \text { kas ve vel-wa=a is pa:ko bo } \\
\text { DSC } & \text { NEG DIR look.at-NMLZ=3N ART.PL dog because } \\
\text { jayna } & i: d e, \quad \text { i:de } \quad \underline{\text { sal-na }=\underline{a}} \\
\text { DSC } & \text { PRO.1INCL PRO.1INCL } & \text { look.for-DIR }=3 \mathrm{~N}
\end{array}
$$

"(When the jaguar notices that there are humans near), it does not look at the dogs anymore, but it's us, it’s us it looks for." (lit. "We are its lookedfor/sought ones.")

Despite the absence of the actor/inverse cleft in the modern language, we would model the source construction as a non-hierarchical set of choices, with every

20 We thank Haude for bringing these examples to our attention, and point out that Haude herself provides the literal translation of the underlined clause in (15), suggesting that she also analyzes this as a synchronic cleft. 
quadrant allowing speakers to select between the undergoer cleft (antecedent to Direct) and the actor cleft (antecedent to Inverse), in addition to whatever other main clause grammar might have existed alongside these clefts (this is unknown because it has left no identifiable reflexes in the modern language). This situation, modeled here in Figure 21, would be reminiscent of the active-passive source alternations modeled in Section 2.1, Figure 4. These two sources were subsequently restricted to specific domains, as shown in Figure 22, creating the hierarchy observed today (note that we do not model the grammatical restrictions found in the Nonlocal domain, but this is merely for expository convenience).

\begin{tabular}{c|c|c|}
\multicolumn{1}{c}{ SAP P } & $3 \mathrm{P}$ \\
\cline { 2 - 3 } SAP A & $\begin{array}{c}\text { UNDERGOER/ACTOR } \\
\text { CLEFTS }\end{array}$ & $\begin{array}{c}\text { UNDERGOER/ACTOR } \\
\text { CLEFTS }\end{array}$ \\
\cline { 2 - 3 } $3 \mathrm{~A}$ & $\begin{array}{c}\text { UNDERGOER/ACTOR } \\
\text { CLEFTS }\end{array}$ & $\begin{array}{c}\text { UNDERGOER/ACTOR } \\
\text { CLEFTS }\end{array}$ \\
\hline
\end{tabular}

Figure 21: No hierarchy - undergoer and actor clefts available in all quadrants.

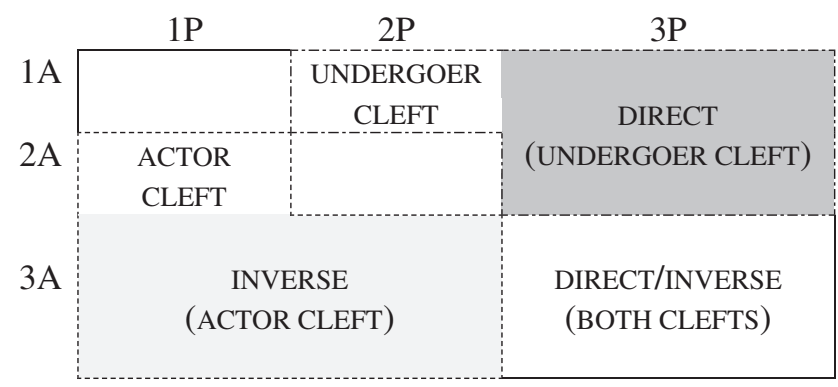

Figure 22: The modern distribution of clefts creates an obligatory hierarchy.

While the change from Figures 21 to 22 is an accurate description of the formal distribution of both clefts, this in itself does not explain why each cleft was restricted to its particular distribution. Unlike the passive/active source, a pair of clefts does not obviously carry within it the functional seeds of the hierarchy, as there is no obvious reason why the undergoer cleft should become restricted to the Direct quadrant and the actor cleft to the Inverse quadrant, nor, for that matter, why each would also be restricted to subsets of the Local and Nonlocal quadrants. In other languages where clefts have become either main clause 
focus constructions or unmarked main clauses, there is nothing in the descriptions that suggests an asymmetry in their use that might serve as the seeds of the hierarchy observed in modern Movima. ${ }^{21}$

In the absence of either a clear motivation or a clear mechanism, one might speculate that possessors tend to be definite, and definiteness is, in turn, associated with pronouns, yielding a preponderance of pronouns and definite arguments in the possessor > Proximate position. Further, when one puts an argument into focus, it is generally against a backdrop of presupposed (and therefore given, or definite) knowledge; as such, the source construction would theoretically have had a preponderance of indefinite $\mathrm{S}>$ Obviative arguments alongside a preponderance of definite possessor $>$ Proximate arguments. When this possessor slot was reanalyzed as the Proximate argument of a transitive predicate, one could imagine that speakers built on this asymmetry and began to allow only the most given/topical participants to occur in that slot. From this basis, the bias would have arisen for the always given/topical speech act participant to obligatorily occupy the Proximate slot, which would have automatically created the hierarchical distribution of the former clefts in the Direct and Inverse quadrants. Even in modern Movima, text show a preponderance of pronominal arguments in Proximate position (Haude 2012).

However, it is not clear how either the Local hierarchy of $1>2$ or the Nonlocal animacy hierarchy human > animate > inanimate would be a further extension of the information status of higher-ranking participants. We know of no studies that address this question directly, but it is not intuitively obvious to us that humans are more frequently anaphorically given than are animates, nor that animates are in turn more frequently anaphorically given than are inanimates. As mentioned before (and modeled in Figure 20), in Movima, the Nonlocal hierarchy is not applied consistently: whenever the actor is higher ranked than the undergoer, the construction will always be Direct; and whenever the actor is inanimate and the undergoer animate or human, the clause will always be Inverse. However, ranking of human $\mathrm{N}>$ animate $\mathrm{N}$ does not predict the grammar when the actor is animate and the undergoer human - in such cases, the outcome is equally likely to be Direct (counter to the expected hierarchy) as it is to be Inverse (cf. discussion in Haude 2010: 301-304, 2012: 172-173). Turning to the Local quadrant, since both first and second person are

21 Although there is also no evidence to the contrary, in that we are not aware of any studies of the distribution of such constructions with reference to speech act participants, animacy, or any other category of inherent topicality in languages like Celtic, Japanese, Rendille, or any others in which old cleft constructions have become focus constructions. This is a topic that merits further research. 
inherently given, definiteness is still less likely to motivate the ranking of $1>2$ in the Local quadrant, leaving us with another open question for future research: what might have motivated speakers to privilege first person for the single Proximate position, leaving second person to be Obviative regardless of semantic roles?

A second possible explanation is perhaps more speculative, but is interesting given that there are other hierarchical systems found in the area: Movima speakers might have modeled the distribution of these reanalyzed cleft constructions on a prior hierarchical system that has since been lost, or on a hierarchical system in a geographically nearby language (Reyesano and Movima are spoken quite close to each other, although there is no evidence of lexical borrowings between the two, nor reports of modern bilinguals who speak both languages).

Returning to the larger typological question that is our focus in this paper, we can now see that this source brings with it certain properties that are unique among the Inverse systems attested so far: First, there are two direction morphemes, a Direct and an Inverse, which have their source etymologically in something like participant nominalizations or relative clause constructions, with the actor nominalizer/relative clause marker becoming the Inverse morpheme and the undergoer nominalizer/relative clause marker becoming the direct morpheme. Second, the argument structure of the cleft source creates an asymmetry between Proximate and Obviative as grammatical roles, with the Proximate coming from the internal argument of the nominalization/relative clause and the Obviative coming from the $S$ of the cleft construction; given that the $S$ of intransitive clauses also comes from the $S$ of a cleft construction, this has the effect of aligning the grammatical properties of $S$ and Obviative, in opposition to the Proximate. However, the source construction does not provide a clear motivation for the creation of the attested hierarchy effects, making this a case in which we cannot make the strong claim that the hierarchy effects are epiphenomenal.

\subsection{Summary of patterns}

At this point, we pause between the presentation of data and the discussion to come of what we learn from these data so that we can take stock of the diverse modern patterns that we see arising from these varied sources. Table 8 presents these findings in condensed form, with the different sources listed in the leftmost column and the row across the top listing the various synchronic properties associated with hierarchical systems. Each cell of the table then expresses (i) whether or not the source in question gives rise to this feature, and (ii) if so, 
Table 8: Correlating sources with resulting structural patterns.

\begin{tabular}{|c|c|c|c|c|c|c|c|}
\hline \multirow[t]{2}{*}{ Sources } & \multirow{2}{*}{$\begin{array}{l}\text { Direction } \\
\text { marking }\end{array}$} & \multirow{2}{*}{$\begin{array}{l}\text { Case } \\
\text { marking }\end{array}$} & \multirow{2}{*}{$\begin{array}{l}\text { Alignment } \\
\text { with S }\end{array}$} & \multicolumn{3}{|c|}{ Direction domains } & \multirow{2}{*}{$\begin{array}{l}\text { Source of } \\
\text { Hierarchy } \\
\text { Effects }\end{array}$} \\
\hline & & & & Local & Mixed & Nonlocal & \\
\hline Passive & $\begin{array}{l}\text { yes } \\
\text { (PASS) }\end{array}$ & $\begin{array}{l}\text { yes } \\
\text { (oBv A) }\end{array}$ & PROX & $\begin{array}{l}\text { unique } \\
\text { DIRECT } \\
\text { INVERSE }\end{array}$ & (yes<) & yes & Topicality \\
\hline Deixis & $\begin{array}{l}\text { yes } \\
\text { (CISLoCATIVE) }\end{array}$ & no & $\mathrm{N} / \mathrm{A}$ & $\begin{array}{l}\text { only } \\
\text { INVERSE }\end{array}$ & yes & no & $\begin{array}{l}1 / 2= \\
\text { CISLOCATIVE }\end{array}$ \\
\hline Loss of 3 & no & no & PROX & (yes<) & yes & no & $3=\varnothing$ \\
\hline Huastec Loss of 3 & $\begin{array}{l}\text { yes } \\
\text { (LOCATIVE) }\end{array}$ & no & $\begin{array}{l}1 S=\text { oBV } \\
2 / 3 \text { none }\end{array}$ & (yes<) & yes & no & $\begin{array}{l}3>\varnothing \\
\text { LOCATIVE }\end{array}$ \\
\hline Reyesano other 3 & (from $3 A$ ?) & $\begin{array}{l}\text { no } \\
\text { (lost) }\end{array}$ & PROX & $\begin{array}{l}\text { yes } \\
(<?)\end{array}$ & yes & no & $\begin{array}{l}\text { no } 3 \text { clitic; } \\
\text { clitic order? }\end{array}$ \\
\hline Cleft & yes & $(\mathrm{S} \neq \mathrm{PSR})$ & OBV & yes & yes & yes & ?? \\
\hline
\end{tabular}

from what part of the source this feature arises. Note that the Huastec loss of 3 is treated separately from the general case because it also includes a locative source for a direction marker, and the Reyesano case is also separated because hierarchical indexation arguably comes not from the loss of 3, but rather the occurrence of a " $3 \mathrm{~A}$ " morpheme in another location in the verb - a variable that could bring its own quirks.

The first clear conclusion that follows from Table 8 is that the grammar that encodes hierarchical alignment consistently reflects the grammar of the source constructions, in that they already contained the grammatical forms that were later reinterpreted as markers of hierarchical alignment. In particular, the passive, deixis, and cleft sources have source morphemes (the passive, deixis, and cleft morphology itself) that become interpreted as markers of Inverse; the cleft source has a second morpheme that becomes interpreted as a marker of Direct. Only the passive > Inverse source gives rise to Obviative case marking, and that only on the oblique > Obviative A in the Inverse construction, leaving both arguments unmarked in the active > Direct. In this context, we note that the simultaneous rise and reanalysis of an antipassive $>$ Direct, in opposition to the passive > Inverse, would create a situation in which both the A of Inverse and the $\mathrm{P}$ of the Direct would be marked as oblique $>$ Obviative. ${ }^{22}$

It is not a traditional part of the typology of hierarchical alignment to ask which transitive argument aligns with S, but it is noteworthy that the answer

22 For a possible example of this, see Zahir's work in progress on Coast Salish. 
varies depending on source. The passive > Inverse source creates alignment between $\mathrm{S}$ and notional $\mathrm{P}$ (itself $\mathrm{S}$ of the passive construction in the source), and the grammar of this alignment continues after reanalysis in the form of $\mathrm{S}=$ prox of Inverse (which in some languages would then go on to become the absolutive category in an ergative-absolutive clause type). Note that the alignment of the etymological active > Direct clause is not affected, so if it was already nominative-accusative $(A=S)$, then there will be a unified category of $\mathrm{S}=$ prox; if the alignment did not have $\mathrm{A}=\mathrm{S}$ i. e., if it was either ergativeabsolutive already, or else if there is a split intransitive system that does not yield a consistent $\mathrm{S}$ category), then the reanalysis of the passive as Inverse will bring the Proximate $\mathrm{P}$ into alignment with $\mathrm{S}$, but not with $\mathrm{A}$ of the active $>$ direct clause, leading to a lack of unity in the alignment properties of Proximate.

Table 9 gives the full list of languages considered in this paper, grouping them based on similarity of sources and then merely listing the resultant hierarchy effects. Considering the variety of sources and the variety of motivations (or, in some cases, lack of motivation) for the resultant hierarchical patterns, we see something interesting: the passive source uniformly works towards the SAP > 3 hierarchy (not completely in Quileute), but while the deictic source does this for some examples (Kuki-Chin and Dravidian), in other cases, it separates first person from 2 and 3 (Molalla and Nez Perce). The null third person source also gives the

Table 9: Correlating sources with resulting hierarchies.

\begin{tabular}{|c|c|c|c|}
\hline Sources & Source of Hierarchy & Resultant Hierarchy & Later Hierarchy \\
\hline Quileute & Topical $P \Rightarrow$ passive & $2>3$ & \\
\hline Nitinaht, Makah & Topical $P \Rightarrow$ passive & $\mathrm{SAP}>3$ & \\
\hline S. Tiwa, Nuuchah. & Topical $P \Rightarrow$ passive & $\mathrm{SAP}>3$ & \\
\hline A. Tewa, Yana & Topical $P \Rightarrow$ passive & $\mathrm{SAP}>3$ & \\
\hline Sizang, Tiddim & SAP $P \Rightarrow$ CISLOCATIVE & $\mathrm{SAP}>3$ & \\
\hline Molalla & $1 \mathrm{P} \Rightarrow$ CISLOCATIVE & $1>2,3$ & \\
\hline Nez Perce & $2 \rightarrow 1 \Rightarrow$ CISLOCATIVE & $1>2$ & \\
\hline Kui & SAP $P \Rightarrow$ "give to SAP" & $\mathrm{SAP}>3$ & \\
\hline Cariban & $3 A=\varnothing, 3 P \Rightarrow \varnothing$ & $\mathrm{SAP}>3$ & \\
\hline Panare & $\begin{array}{l}3 A=\varnothing ; 3 P \Rightarrow \varnothing \\
2 \rightarrow 1>2 A ; 1 \rightarrow 2 \text { mixed }\end{array}$ & $2>1>3$ & \\
\hline Huastec & $\begin{array}{l}3 P=\varnothing ; 3 A \Rightarrow \varnothing \\
1 \rightarrow 2 \Rightarrow 1 A ; 2 \rightarrow 1 \Rightarrow 1 P\end{array}$ & $\begin{array}{l}\text { (Colonial) } \\
1 \mathrm{PL}>2>1 \mathrm{SG}=3\end{array}$ & $\begin{array}{l}(\mathrm{SLP}) \\
1>2 \mathrm{PL}>2 \mathrm{SG}>3\end{array}$ \\
\hline Reyesano & $\begin{array}{l}\text { 3A marked elsewhere; } \\
\text { (clitic order } 1>2>3 \text { ) }\end{array}$ & $2>1>3$ & \\
\hline Movima & $\begin{array}{l}\text { OBV }<\text { FOCUS } \\
\text { PROX }<\text { TOPIC }\end{array}$ & $\begin{array}{l}1>2>3 \\
\text { (hum/anim > inan) }\end{array}$ & \\
\hline
\end{tabular}


SAP > 3 hierarchy, but is unpredictable in its treatment of 1 and 2. Finally, the cleft source, which results in non-hierarchical grammar for all cases except Movima, gives us the same SAP $>3$ core, alongside its rigid ranking of $1>2$ in the Local quadrant and human/animate > inanimate in the Nonlocal quadrant. This finding seems to endorse DeLancey's $(1981,2001)$ claim, that the only really reliable crosslinguistic pattern in hierarchies is the ranking SAP $>3$.

\section{Consequences for the study of so-called hierarchy effects}

We now turn to the question of cognitive plausibility of "the hierarchy" that is revealed by these data. Aside from the consistency of the pattern in which SAP > 3, there is little coherence. In the Local quadrant, we find every possible combination: $1>2,2>1$, each of the Local situations has unique grammar, all Local situations are Direct, all are Inverse, and half are Direct or Inverse while the other half have unique grammar; plurals are sometimes not relevant, sometimes ranked higher than singulars, sometimes ranked lower than singulars, and sometimes singulars and plurals seem to be entirely independent of one another (cf. Colonial Huastec). Further, it is clear that not all the grammatical devices that mark direction in a given language have to use the same hierarchy: for example, in Huastec, the Inverse morpheme marks all Local scenarios (thereby ranking $1=2$ ), yet the personal proclitics are pretty clear in ranking $1>2$.

One of the things that we take from this set of examples is that the loss of a single prefix (even due to phonological erosion) in a single cell of a paradigm could change the ranking of the language-specific hierarchy. It is not clear how such changes could be motivated by any kind of universal hierarchy. We have to wonder if the systemic logic that linguists seek to find in language data reflect realities that speakers attend to (whether consciously or subconsciously), or if we are not simply using the tools of our approach to science to impose logic on patterns that are really more atomistic in the minds of speakers. Certainly the hierarchies that derive from changes that lead to null third persons are affected by the evolution of other inflections, sometimes cell by cell in the Local quadrant, yielding patterns that are odd when viewed from the perspective of the hierarchy. To return to the example of Huastec, the Colonial version of the language shows a hierarchy of 1PL $>2>1 \mathrm{SG}=3$, with 1SG on the bottom of the SAP hierarchy because (i) the $3 \rightarrow 1$ cell is the only one that has not yet lost the $3 \mathrm{~A}$ marker, and (ii) in the Local quadrant, the second person forms continue to co-occur with both 1sGA and 1sGP. By SLP Huastec, the 1sG form is all that remains in all of these cells except 
when $1 \rightarrow 2 \mathrm{PL}$. Do we really want to believe that more recent generations of speakers have cognitively shifted 1sG to merge with 1PL at the top of the hierarchy, then split the formerly unified hierarchical category of 2 to become 2PL > 2sG? Turning to the Cariban examples, once the third person morphemes are gone in the Direct and Inverse quadrants, the analysis of the hierarchy varies by language, with extension of the $2 \rightarrow 3$ prefix to the situation where $2 \rightarrow 1$. Is this a defining moment for "the hierarchy" in the minds of the speakers who made this change (or perhaps in their children?), or is it just a local change in one form in the paradigm? Given the many other changes that happen in these paradigms (see Gildea 1998: 94-95 for a sampling of many others that do not seems to carry similar theoretical significance), to give these particular changes such importance seems somewhat facile theoretically.

Another perspective that we might take from these examples is the distinction between inherited patterns and innovations. For example, the pattern "all situations with an SAP undergoer are marked Inverse" is inherited from the deictic source, and similarly, the SAP > 3 pattern comes automatically from the null third person source. In contrast, the source does not entail that Huastec would lose its 3A clitic when interacting with SAP undergoers, nor does it entail that nearly all clitic combinations in the Local quadrant would simplify to a single marker (whether of first or second person). Similarly, the cleft source does not entail any hierarchical asymmetry, and even though Givón offers a theoretical justification for why a passive would become obligatory just in the Inverse quadrant, there are also examples in which the passive does not limit itself in this way, but goes on to become a tense-aspect conditioned ergative construction. In fact, in Wayana, Apalaí, and Tiriyó (Cariban), the passive that becomes past tense (Gildea 1997) could have modeled itself after the existing hierarchical indexation system in all three languages, and thus have created a new instantiation of the hierarchy, but it did not.

At this point, it feels that we have just begun to scratch the surface of this question. We have examined only a handful of the known hierarchical systems in the world, those for which scholars have reconstructed the source grammar that was remodeled into these systems. Nevertheless, we have not closely examined the origins of any of the hierarchical systems that instantiate violations of the universal hierarchy, or (beyond perhaps Huastec) where different grammatical elements in the same language - or even in the same construction in a given language - appear to instantiate different rankings of participants, and thereby to follow more than one hierarchy at the same time. Lastly, we ask the question of where one might turn next in order to create a better understanding of where hierarchy effects come from, and in particular how the counter-universal hierarchical patterns come to exist. The literature is rich 
with strange hierarchies, as seen in Silverstein's (1976) original set of examples (which do not consistently yield the neat, clean hierarchies we see in typology textbooks), or Zúñiga's (2006, 2008) and Macaulay's (2009) discussion of hierarchies in Algonquian, or more recent statements of general concern like those in Richards and Malchukov (2008). Table 10 summarizes the sorts of synchronic problems that have been described for "The Hierarchy".

Table 10: The hierarchy as analytical tool.

\begin{tabular}{ll}
\hline Hierarchy works & Hierarchy does not (really) work \\
\hline Emerillon verbal prefix selection & Belhare verbal dual marker chi \\
$1 / 2>3$ & idiosyncratic person-number combinations \\
Plains Cree verbal prefix selection & Plains Cree verbal suffix selection \\
$2>1>3$ & $1 \mathrm{PL}>2 \mathrm{PL}>3 \mathrm{ANIM}>1 \mathrm{SG} / 2 \mathrm{SG}>3$ INAN \\
Tagalog nominative assignment & Aguaruna case marking \\
prominent $>$ non-prominent & $1 \mathrm{SG}>2 \mathrm{SG}>1 \mathrm{PL} / 2 \mathrm{PL}>3$ \\
Yurok $\varnothing$ vs. ACC marking on $\mathrm{P}$ argument & Ik NOM VS. ACC marking on P argument \\
$1 / 2>3$ & direct/local NOM, inverse/nonlocal ACC \\
\hline
\end{tabular}

It is well known that speech act participants resist ranking attempts across languages. However, even 3rd-person participants resist consistent ranking attempts across languages, across different constructions within languages, and within given constructions within languages. Several variables appear to be independent, such that they interact rather than being ranked in a linear fashion: animacy, definiteness, number, person, and discourse topicality are not "slots" in a single hierarchy.

Although this is not the venue to address any of these concerns in detail, we conclude by pointing to two examples of language families that instantiate quite different hierarchies in different domains of their grammar. In both cases, it seems unlikely that a universal hierarchy has guided the creation of all these divergent patterns from a unified ancestor, whatever the grammar of that ancestor might have looked like. First, consider the various rankings of just 1 , 2, and 3 as instantiated in a range of Algonquian languages (Table 11), and then the various rankings of these same persons as instantiated in the verbal indexation patterns of a range of Kiranti languages (Table 12), both from WitzlackMakarevich et al. (this issue).

Once a "hierarchical system" is in place, further changes appear to be multidirectional. Changes in Local prefixes in Cariban are language-specific (Gildea 1998: 82-84): the $2 \rightarrow 1$ marker becomes a 2 A marker $(2>1)$ in Hixkaryana and Panare, a 1P marker $(1>2)$ in Yukpa, and both markers $(1=2)$ in Waimiri-Atroari; 
Table 11: Pairwise ranking of person values in the Algonquian languages.

\begin{tabular}{llll}
\hline Language & $\mathbf{1}$ vs. 2 & $\mathbf{1}$ vs. $\mathbf{3}$ & $\mathbf{2}$ vs. 3 \\
\hline Arapaho & $2>1$ & diverse & $2>3$ \\
Atikamekw & diverse & diverse & $3>2$ \\
Blackfoot & $2>1$ & $1>3$ & diverse \\
Cheyenne & $2>1$ & diverse & diverse \\
Cree (Plains) & diverse & diverse & diverse \\
Micmac & diverse & diverse & $2>3$ \\
Munsee & $2>1$ & diverse & diverse \\
Ojibwa (Eastern) & $2>1$ & $1>3$ & $2>3$ \\
Passamaquoddy & $2>1$ & Diverse & $2>3$ \\
\hline
\end{tabular}

Table 12: Pairwise ranking of person values in the Kiranti languages.

\begin{tabular}{lllll}
\hline Language & Tense & $\mathbf{1}$ vs. 2 & $\mathbf{1}$ vs. $\mathbf{3}$ & $\mathbf{2}$ vs. $\mathbf{3}$ \\
\hline Bahing & any & $1>2$ & $1>3$ & $2>3$ \\
Bantawa & any & none & $1>3$ & $2>3$ \\
Belhare & any & none & $3>1$ & none \\
Camling & any & $1>2$ & $1>3$ & $2>3$ \\
Chintang & any & none & $1>3$ & $2>3$ \\
Dumi & PST & diverse & none & $2>3$ \\
Jero & any & diverse & $3>1$ & $2>3$ \\
Kõic & NPST & none & none & none \\
& PST & none & $1>3$ & none \\
Koyi & any & $1>2$ & $1>3$ & diverse \\
Kulung & NPST & none & $1>3$ & $3>2$ \\
& PST & none & $1>3$ & $2>3$ \\
Limbu & any & $2>1$ & $1>3$ & $2>3$ \\
Wambule & any & diverse & $1>3$ & $2>3$ \\
Yakkha & any & none & $1>3$ & none \\
Yamphu & any & $2>1$ & $3>1$ & diverse \\
\hline
\end{tabular}

the $1 \rightarrow 2$ marker becomes a $2 \mathrm{P}$ marker $(2>1)$ in Panare and Yukpa but changes idiosyncratically in five other languages. There might have been changes in the Nonlocal paradigm for Tupí-Guaraní, i. e., possibly the Tupinambá examples of Nonlocal alternations cited in Payne (1994).

Where do we go from here? This paper has provided some evidence supporting the claim that the formal properties of constructions sensitive to semantic/ referential factors are largely predictable from knowing their sources and the mechanisms of change. The semantic/referential properties relevant to each 
construction are inherited from its source; additional features become relevant as these constructions evolve further, and it is an empirical question whether there are consistent crosslinguistic patterns (i. e., directionality) to such additions. However, we clearly need fuller synchronic descriptions of local versus global strategies for determining grammatical treatment of core arguments. (Local strategies only consider features of the argument in question - e.g., (largely) Spanish differential object marking - whereas global strategies consider features of both the argument in question and those of its companion argument(s).) Each individual case of global strategies (recently termed "coargument sensitivity," Witzlack-Makarevich et al. this issue) needs to be computed separately; "The Hierarchy" now becomes a falsifiable (and falsified) hypothesis as to what the relevant variables are and how they are ranked visà-vis one another. Probabilistic multivariate models can consider degrees of interdependence amongst (logically independent) types of variables (Bresnan and Ford 2010; Schikowski 2013), which will in turn lead to better analyses of the grammar of individual languages.

Acknowledgments: For support during the conceptualization and writing of this article, we gratefully acknowledge the support of the EuroCORES / EuroBABEL Collaborative Research Project Referential Hierarchies in Morphosyntax, and to our colleagues in that project, especially Balthasar Bickel, Katharina Haude, and Anna Siewierskat. Spike Gildea also acknowledges support from the National Science Foundation, grant no. BCS-0936684 and from the Collegium de Lyon. For their many thoughtful and stimulating comments on earlier versions of this work, we thank Katharina Haude, Antoine Guillaume, Alena Witzlack, and Françoise Rose; comments from two anonymous reviewers were also quite helpful. Any remaining mistakes are our own.

\section{References}

Berman, Howard. 1996. The position of Molala in Plateau Penutian. International Journal of American Linguistics 62(1). 1-30.

Bickel, Balthasar. 2008. On the scope of the referential hierarchy in the typology of grammatical relations. In Greville Corbett \& Michal Noonan (eds.), Case and grammatical relations: Studies in honor of Bernard Comrie, 191-211. Amsterdam \& Philadelphia: John Benjamins.

Bresnan, Joan \& Marilyn Ford. 2010. Predicting syntax: Processing dative construction in American and Australian varieties of English. Language 86. 168-213.

Comrie, Bernard. 1989 [1981]. Language universals and linguistic typology: Syntax and morphology, 2nd edn. Chicago: Chicago University Press. 
Dahl, Eystein. 2016. The orgin and development of the Old Indo-Aryan pedicated -tá construction. In Eystein Dahl \& Krzysztof stroński (eds.), Indo-Aryan Ergativity in Typological and Diachronic perspective. Amsterdam: John Benjamins.

DeLancy, Scott. 1981. An interpretation of split ergativity and related patterns. Language 57. 626-657.

DeLancey, Scott. 2001. Lectures on functional syntax. Revised notes for the Summer School held at the University of California, Santa Barbara, July 2001. http://darkwing.uoregon. edu/ delancey/sb/fs.html (accessed 22 December 2015).

Derbyshire, Desmond. 1987. Areal characteristics of Amazonian languages. International Journal of American Linguistics 53. 311-326.

Dixon, R. M. W. 1994. Ergativity. Cambridge: Cambridge University Press.

Gildea, Spike. 1997. Evolution of grammatical relations in Cariban: How functional motivation precedes syntactic change. In T. Givón (ed.), Grammatical Relations: A Functionalist Perspective, 155-198. Amsterdam: John Benjamins.

Gildea, Spike. 1998. On reconstructing grammar: Comparative Cariban morphosyntax. Oxford: Oxford University Press.

Gildea, Spike. 2002. Reconstructing Pre-Proto-Tupi-Guarani main clause grammar. In Atas do Encontro Internacional de Pesquisadores de Línguas Indígenas, 315-326. Belem: Universidade Federal do Para.

Gildea, Spike. 2009. Reconstructing sources for hierarchical alignment in main clause grammar. Paper presented at the 8th Biennial Conference of the Association for Linguistic Typology, UC Berkeley, 23-26 July.

Gildea, Spike. 2012. Linguistic studies in the Cariban family. In Lyle Campbell \& Veronica Grondona (eds.), Handbook of South American languages, 441-494. Berlin \& Boston: De Gruyter Mouton.

Gildea, Spike. 2013. Motivated versus unmotivated pathways in the evolution of main clause alignment patterns. Paper presented at the 10th Conference of the Association for Linguistic Typology, University of Leipzig, Leipzig, Germany, 15-18 August.

Gildea, Spike \& Katharina Haude. 2011. The origins of the Movima hierarchical alignment: internal reconstruction. Paper presented in the Workshop: Diachronic Syntax, International Congress on Historical Linguistics. Osaka, July 25-29.

Givón, T. 1994. Introduction. In T. Givón (ed.), Voice and inversion, 3-44. Amsterdam \& Philadelphia: John Benjamins.

Givón, T. 2001. Syntax: An introduction, 2 vols. Amsterdam \& Philadelphia: John Benjamins.

Guillaume, Antoine. 2009. Hierarchical alignment and split transitivity in Reyesano. International Journal of American Linguistics 75(1). 29-48.

Guillaume, Antoine. 2010. How ergative is Cavineña? In Spike Gildea \& Francesc Queixalós (eds.), Ergativity in Amazonia, 97-120. Amsterdam \& Philadelphia: John Benjamins.

Guillaume, Antoine. 2011. Third person agreement and passive marking in Tacanan languages: a historical perspective. International Journal of American Linguistics 77(4). 521-536.

Guillaume, Antoine. 2014. The decay of ergativity in Tacana (Tacanan family, Amazonian Bolivia). Syntax of the World's Languages VI, University of Pavia, Pavia, Italy. 8-10 September, 2014.

Guillaume, Antoine. Forthcoming. From ergative case-marking to hierarchical agreement: A tentative reconstruction of the argument-marking system in Reyesano (Tacanan, Bolivia). 
In Spike Gildea \& Joana Jansen (eds.), Diachrony of hierarchical systems. Amsterdam \& Philadelphia: John Benjamins.

Harris, Alice \& Lyle Campbell. 1995. Historical syntax in cross-linguistic perspective. Cambridge: Cambridge University Press.

Haude, Katharina. 2006. A grammar of Movima. Nijmegen: Radboud University dissertation. Haude, Katharina. 2009. Hierarchical alignment in Movima. International Journal of American Linguistics 75(4). 513-532.

Haude, Katharina. 2010. The intransitive basis of Movima clause structure. In Spike Gildea \& Francesc Queixalós (eds.) Ergativity in Amazonia, 285-315. Amsterdam \& Philadelphia: John Benjamins.

Haude, Katharina. 2012. Saillance inhérente et saillance discursive en movima. Faits de Langues 39. 169-180.

Heine, Bernd \& Mechthild Reh. 1984. Grammaticalization and reanalysis in African languages. Hamburg: Helmut Buske.

Iwasaki, Shoichi. 1993. Functional transfer in the history of Japanese language. In Patricia Clancy (ed.), Japanese/Korean linguistics 2, 20-32. Stanford, CA: CSLI Publications.

Jensen, Cheryl. 1998. Comparative study: Tupí-Guaraní. In Desmond Derbyshire \& Geoffrey Pullum (eds.), Handbook of Amazonian languages, Vol. 4, 489-618. Berlin \& New York: Mouton de Gruyter.

Klaiman, M. H. 1991. Grammatical voice. Cambridge: Cambridge University Press.

Kondić, Snježana. 2012. A grammar of South Eastern Huastec, a Mayan language from Mexico. Sydney \& Lyon: University of Sydney \& Université Lumière Lyon 2 dissertation.

Macaulay, Monica. 2009. On prominence hierarchies: Evidence from Algonquian. Linguistic Typology 13(3). 357-389.

Meira, Sérgio, Spike Gildea \& Berend Hoff. 2010. On the origin of ablaut in the Cariban family. International Journal of American Linguistics 76. 477-515

Mithun, Marianne. 2007. Integrating approaches to diversity: Argument structure on the NW coast. In Yoshiko Matsumoto, David Oshima, Orrin Robinson \& Peter Sells (eds.), Diversity in language: Perspectives and implications, 9-36. Stanford, CA: CSLI Publications.

Mithun, Marianne. 2012. Core argument patterns and deep genetic relations: Hierarchical systems in Northern California. In Bernard Comrie (ed.), Typology of argument structure and grammatical relations, 258-294. Amsterdam \& Philadelphia: John Benjamins.

Payne, Doris. 1994. The Tupí-Guaraní inverse. In Barbara Fox \& Paul Hopper (eds.), Voice, 313-340. Amsterdam \& Philadelphia: John Benjamins.

Payne, Thomas \& Doris Payne. 2013. A typological reference grammar of Panare. Leiden: Brill.

Pharris, Nicolas. 2006. Winuunsi tm talapaas: A grammar of the Molalla language. Ann Arbor, MI: University of Michigan dissertation.

Richards, Marc \& Andrej Malchukov (eds.). 2008. Scales (Linguistische Arbeitsberichte 86). Leipzig: University of Leipzig.

Rose, Françoise. 2013. Deconstructing the person hierarchy as an explanation of the synchrony and diachrony of Tupi-Guarani indexing systems. Paper presented at the 10th Conference of the Association for Linguistic Typology, University of Leipzig, Leipzig, Germany, 15-18 August.

Rude, Noel. 1985. Studies in Nez Perce grammar and discourse. Eugene, OR: University of Oregon dissertation.

Schikowski, Robert. 2013. Object-conditioned differential marking in Chintang and Nepali. Zürich: University of Zürich dissertation. 
Siewierska, Anna. 2004. Person. Cambridge: Cambridge University Press.

Silverstein, Michael. 1976. Hierarchy of features and ergativity. In R. M. W. Dixon (ed.), Grammatical categories in Australian languages, 112-171. Canberra: Australian Institute of Aboriginal Studies.

Steever, Sanford. 1993. Analysis to synthesis. The development of complex verb morphology in the Dravidian languages. Oxford: Oxford University Press.

Stern, Theodore. 1984. Sizang (Siyin) Chin texts. Linguistics of the Tibeto-Burman Area 8(1). 43-58.

de Tapia Zenteno, Carlos. 1767. Noticia de la lengua huasteca. Biblioteca Mexicana.

Zavala, Roberto. 1994. Inverse alignment in Huastec. Función 15/16. 27-81.

Zúñiga, Fernando. 2006. Deixis and alignment: Inverse systems in indigenous languages of the Americas. Amsterdam \& Philadelphia: John Benjamins.

Zúñiga, Fernando. 2008. How many hierarchies, really? Evidence from several Algonquian languages. In Marc Richards \& Andrej Malchukov (eds.), Scales, 99-129. Leipzig:

University of Leipzig. 